Papers and Proceedings of the Royal Society of Tasmania, Volume 108

(ms. received $3,12.1973)$

\title{
OBSERVATIONS ON SOME TASMANIAN FISHES: PART XX
}

by E.O.G. Scott, Launceston

(with four text-figures)

\section{ABSTRACT}

Three species, Atypichthys strigatus (Günther), Kathetostoma giganteum Haast, Navodon multiradiata (Günther), are reported for the first time from Tasmania. The inclusion in the local list of Vincentia novaeholZandiae (Valenciennes), on which doubt had been cast by recognition of the validity of $V$. Zemprieri (Johnston), is confirmed.

General observations are made on the following species: Squatina australis Regan, Alabes dorsalis (Richardson), Alabes rufus (Macleay), Anguizla reinhardtii Steindachner, Scomis lineolatus Kner, Kathetostoma Zaeve (Bloch \& Schneider), Gnathanacanthus goetzeii Bleeker. A key to the Tasmanian species of Alabetidae is supplied.

\section{INTRODUCTION}

This paper follows the general plan of others in the series. Linear measurements are given throughout in millimetres, the name of the unit commonly being omitted. The symbols $L s$, $L t, T L s$, $T 2 t$ denote standard length, total length, thousandths of standard length, thousandths of total length, respectively. Standard deviation is calculated with $n$ degrees of freedom; derived statistics being computed from the value thus obtained. Registration numbers are those of the Queen Victoria Museum, Launceston. Certain other conventions are noted in earlier contributions.

\section{Family SQUATINIDAE}

The family Squatinidae [Rhinidae of early authors - e.g. Güther (1880), Macleay (1881), Johnston $(1883,1891)$, Boulenger (1910)], with a global temperate and tropical distribution, comprises probably fewer than a dozen species, commonly referred to a single genus, Squatina Duméril, 1806. Tho species have been described from Australia: $S$. australis Regan, 1906 [Check-list distribution New South wales, Victoria, Tasmania, South Australia; Western Austra1ia added by Whitley (1948)], S. tergoceZZata McCulloch, 1914 [Check-list distribution Great Australian Bight, New South Wales; Western Australia added by Whitley (1948), South Australia by Scott (1962)]. The specific distinctness of McCulloch's species has been questioned, e.g., by Lineaweaver \& Backus (1970). [Presumably having in mind the angel shark's well-known habit of lying at times partly buried in mud or sand, these authors derive McCulloch's second binomen (of which he did not note the origin) from tergus, bask, and celo, hidden: the writer would rather guess a formation from tergum, back, and ocellatus $(-a,-u m)$, marked with eyelike spots; in allusion to the conspicuous color pattern of the dorsal surface.] Conventionally, the two Australian species should be distinguishable at sight by the color pattern: however, a Tasmanian example of $S$. australis here noted exhibits an interesting approach in this feature to $S$. tergocelzata, and, judged solely by it, might rather be referred to that species.

\section{Genus SQUATINA}

Squatina Duméril, 1806, Z002. Analyst., 102 and 342. Haplotype, Squalus squatina linné, 1758 . 
(fig. 1)

Squatina australis Regan, 1906, Ann. Mag. Nat. Hist., (7), xviii, 438. Type locality, Port Jackson.

Material. A female, Lt 307 caught at Sidmouth, Tamar River, on 5 October, 1972 by E. Bennett; Q.V.M. Reg. No. 1972/5/578 (donor, E.W. Gatenby). Some dimensions of a female, Lt 1178, netted at a depth of 4-5 m by W. French at Boobyalla Bay in 1940 are also recorded: this specimen is not now available.

Dimensions. Dimensions here given, all expressed as millesimals of total length (TLt), are set out in accordance with the biometric scheme of Whitley (1943), with some additional entries: the value for the 1940 example, where available, is shown in parentheses. Head (H1-H18): H1 169 (136), H2 195 [to anterior border of last gill slit; to tip, 215] (165), H3 42 (44), H4 l66 (144), H5 192 (168), H6 423 (394), H7 23 (14), H8 15 , H9 76 (59), H10 13, 1111 10, 11268 (62), $H 133$ [to anterior border of upper lip; to middle of mouth cleft, 13], H14 134 (130), H15 46, H16 26, H17 80, H18 49. Additional head measurements: length to angle of mouth 95, interspiracular distance 95 ; length of nostril 0 (slit invading exterior profile), interval between ends of 5 th pair of gill slits 81 (84). Body (B1-B9): B1 858 (854), B2 497 (500), B3 653 (664), B4 42, B5 94 (100), B6 23, B7 46 [B8, B9, claspers, not applicable]. Additional body measurements: depth at vent 69 , width (body) at vent 147, length of caudal keel 68. Fins (F1-F22:F1 81 (86), F2 41 (39), F3 26 (31) ['last ray'; here, regularly, posterior border], F4 60 (58), F5 75 (79), F6 37 (38), F7 24 (28), F8 52 (55) [F9-F12 not applicable, no anal; F13, sketch, omitted], F14 261 (278) [usual measurement from insertion; measured from tip of cephalic hook, 326], F15 134, F16 233 (266), F17 101 (119), F18 121, Fig 104 (78), [F20 not applicable; no anal], F2l 109 (106), F22 179 (128). Additional fin measurements: distal border of pectoral 208 (278), 130 (157) [exceptionally, two distal borders, the anterior the larger], distal border of ventral 173 (170), distal border of first dorsal 46 (53), distal border of second dorsal 42 (46), distal border of caudal 117 , posterior border of pectoral 140 (138), posterior border of ventral 104 (78). The length of the forwardly curving anterior border of the exceptionally four-bordered pectoral is, direct 75 (72), between parallels, 72 (68): this border and the anterior portion of the first of the two distal borders constitute a moderately curved hook apparently normally carried beneath the head. Some further dimensions as 5 t of special interest in a squatinid: interpectoral interval, anterior insertion 147 (144), posterior insertion 202; spread of pectorals, at tip of hooks 215 (183), at distal angles (maximum) 521 (579), at posterior angles 319 ; spread of ventrals, maximum 326 (357), at posterior angles 150 ; head, maximum width 261 (225), maximum depth 85; body, maximum depth 107 .

Good agreement obtains between most of the dozen dimensions recorded by McCoy (1879) for his Victorian specimen, a female 3 feet $8 \frac{1}{2}$ inches (112tmm) long, and those of our examples. With all values expressed as $T L t$ we find (Tasmanian material in parentheses, smaller individual first): width across pectorals 5.59 (5:1,579), across ventrals 337 (326, 357); length to first dorsal 652 (653, 664); base ('length'), 'height' [apparently direct distance from base to tip] of first dorsal $34(41,39), 79(75,69)$; base, height of second dorsal $39(37,38), 67(73,63)$; interdorsal $67(60,58)$; width of mouth $93(151,110)$; eye $11(23,14)$; eye to spiracle $17(13,-)$.

Coloration. The following noqes relate to the small sidmouth specimen, no observations on the other individual having been recorded.

Ground color of dorsal surface virtually uniform, somewhat greenish dark brown, except on dorsals and caudal where it is somewhat lighter, noticeably more greenish; ground colour of ventral surface of head, trunk, paired fins faintly greyish off-lhite, of tail dead white; line of demarcation in general sharp, along side of tail the line of brown more or less crenulate. On dorsal surface exposed portions of paired fins and distal margin of second dorsal narrowly margined with white; a number of round white spots 

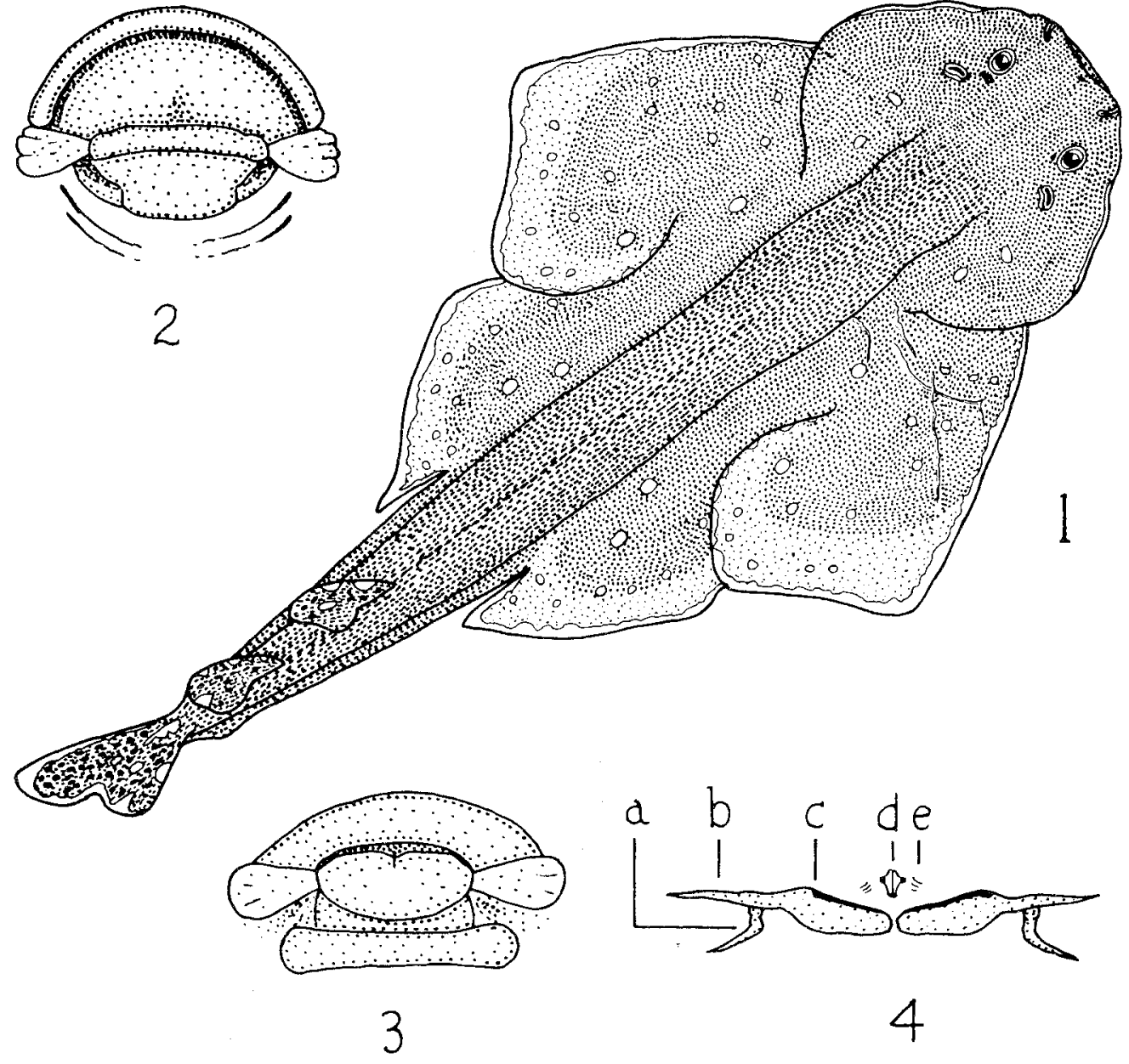

FIG. 1. - Squatina australis Regan, 1906. A female, $307 \mathrm{~mm}$ in total length, from Sidmouth, Tamar River, Dorset (E. Bennett), Queen Victoria Museum Reg. No. $1972 / 5 / 578$, with atypical color pattern, showing some resemblance to that of $S$. tergocellata McCulloch, 1914: x $\frac{1}{2}$.

FIG. 2. - Alabes dorsalis (Richardson, 1845). External features of branchial region in a specimen, $91.1 \mathrm{~mm}$ in total length, from southern Tasmania (B.C. Mollison) $x$ ca 8 .

FIG. 3. - Alabes rufus (Macleay, 1881). External features of branchial region in a specimen, $72 \mathrm{~mm}$ in total length, from southern Tasmania (B.C. Mollison): $x$ ca 10 .

FIG. 4. - Alabes rufus (Macleay, 1881). Pectoral girdle of a cleared and alizarin-stained specimen from Samphire Island, Bass Strait (A.P. Andrews): $x$ ca. 7. Provisional interpretation of skeletal elements: a, dorsal fork of posttemporal; $b$, ventral fork of posttemporal; c, cleithrum (the deeply staining sliver, shown black, may represent a supracleithrum); d, coracoid (the deeply staining regions, shown black, may represent additional elements: at end of transverse arm of cross possibly a scapula; at base possibly a mesocoracoid.) 
(fig. 1), regularly disposed, nearly always paired, about 2,2,15,8 pairs on head, trunk, pectoral, ventral, respectively; diameter of largest about one-third eye diameter; several unpaired spots (fellow not developed?), but no secondary dispersed white spots such as those seen in the photograph of a specimen of $S$. australis given by waite (1921 fig. 26) and reproduced in Munro (1956), Scott (1962); no obvious greyish or greenish dots on head or body, but dorsals with a few and caudal with many small darkish, mainly ovoid spots. On ventral surface four or five irregularly disposed dark smudges in anterior one-third of head; indeterminate dark, somewhat bluish transverse discolorations across throat; a small dark spot on each pectoral, near margin, shortly behind anterior angle; some faint duskiness along posterior distal border of pectoral; two or three dark smudges near anterior half of ventral border, posterior half of this border and most of distal border narrowly edged with white; both dorsals and caudal with white spots and splashes, some of these visually interrupting fin contour.

Comparison with S. tergocelZata. In his description of the holotype of S. tergocelZata, a female $430 \mathrm{~mm}$ long from snout to 'middle of the caudal', McCulloch noted it as differing from $S$. australis as follows: (a) dorsal denticles tricarinate; (b) greater part of [upper surface of] pectorals and ventrals naked; (c) tubercles on snout much larger, differently arranged; (d) interspiracular distance less than interocular; (e) color markings 'altogether different'. In the Sidmouth shark (a) the denticles are unridged, each bearing a single recumbent subcylindrical spinule, much as, but in some cases more acutely pointed than, that figured by McCoy (1879, pl. 34 fig. 1i); (b) about the posterior one-fifth of the upper surface of the pectoral, and a marginal strip, about half as wide as least width of fin, along distal border of the ventral are devoid of denticles; (c) tubercles on snout smaller, fewer than those figured by McCulloch, three behind left eye, one behind right, none bordering inner orbital rim; (d) interspiracular exceeding (1.24) interocular; (e) color pattern of dorsal surface quite different from that commonly attributed to $S$. australis (see above, and fig. 1), exhibiting, especially in the presence of paired spots, what might be regarded as an approach to the typical pattern of $S$. tergocellata. It is of interest to observe that Whitley $(1940,157)$ has mooted the possibility of there being local subspecies of $S$. tergocelzata, noting a specimen trawled near Kiama, New South Wales, as 'differing in colour markings from the Bight type' (McCulloch's Endeavour specimen came from the Great Australian Bight, Long. 127 $\left.128^{\circ} \mathrm{E}.\right)$

A comparison between, on the one hand, McCulloch's figure of S. tergocelzata, and on the other hand, the Sidmouth specimen and the figures of $S$. australis in McCoy (1879 p1. $34 \mathrm{fig.} \mathrm{1)} \mathrm{and} \mathrm{Waite} \mathrm{(1921,} \mathrm{fig.} \mathrm{36)} \mathrm{reveals} \mathrm{some} \mathrm{differences} \mathrm{in} \mathrm{general} \mathrm{form} \mathrm{(data}$ for $S$. australis in parentheses): pectoral with anterior distal border barely (fairly) convex, posterior distal angle rounded (bluntly pointed), posterior distal border slightly sinuous (fairly evenly concave) and equal to or less than (greater than) posterior border: however, the distal border of the ventral, nearly straight in McCulloch's figure and in our specimen, is concave in McCoy's figure, sinuous in Waite's.

\section{Family ALABETIDAE}

The above version of the family name is that used by McCulloch in the Check-1ist (1929); extralimitally, by, among others, Berg (1940), Schultz \& Stern (1948), Greenwood et al. (1966). Alabidae, the form used by Jordan (1923), is adopted by Munro in the Handbook (1957a) and by Scott (1962) in his South Australian catalogue.

The family, which is essentially an Australian one, contains three satisfactorily recognized species of the genus Alabes Cloquet, 1816: (a) A. dorsalis (Richardson, 1845), (b) A. mufus (Macleay, 1881), (c) A. parvulus McCulloch, 1909; of which the first two occur in Tasmania. A fourth species, A. cuvieri Vaillant, 1805 ('Australia', India) is included in thc Check-list and is retained in Whitley's name-1ist (1964), but is dropped from the Handbook. 


\section{Key to Alabetidae Recorded from Tasmania}

A1. Dorsal commencing about above vent (if in advance of vent, nearer to it than to snout tip). Anal commencing well behind vent (by about a head length). Greenish or almost colorless [on preservation turning reddish (alcohol) or yellowish (formalin)]; with, rarely without, 1-9 large spots on side [purplish (alcohol), red (formalin)]; no median stripe.

A. mufus.

A2. Dorsal commencing shortly behind head (nearer to snout tip than to vent). Anal commencing close behind vent ( by about an eye diameter). Brown or blackish brown; no large spots on side; a median dorsal stripe (not always observable after preservation) [in formalin light brown, with or without a purplish cast; fins more or less yellowish, becoming in part whitish distally].

A. dorsalis

\section{Genus ALABES Cloquet, 1816}

Alabes Cloquet, 1816, Dict. Sci. Mat., 1, suppl. 1816, 99, Ex Cuvier MS. Logotype, A. cuvieri Vaillant. Alabes dorsalis (Richardson, 1845).

Cheilobranchus dorsalis Richardson, 1845, Zool. Voy. Erebus and Terror, Eish, 50, pl. $\mathrm{xxx}$, figs 1-5. Type locality, North West Australia.

Distribution. The Check-list gives north-western Australia, Tasmania, South Austra1ia, only the first of which was noted by Macleay $(188 \mathrm{lb}, 266)$ : the Handbook queries South Australia, and Scott (1962) does not include the species in his catalogue for that state. It appears in all published Tasmanian lists, and, fide Johnston $(1883,133)$, in Martin Allport's MS catalogue; Johnston noting 'Tasmanian specimens $90 \mathrm{mil}$. long (Gunn and Günther)'. In Lord (1923) and in Lord and Scott (1924) it is referred to Cheizobranchus Richardson, 1845; in both Johnston's 1ists and in Macleay to Chizobranchus Gunther, 1870 , an emendation of Richardson's name; in Lord (1927) to Alabes. The apparent discontinuous distribution of north-western Australia and Tasmania appears curious. Also, C. aptenodyctum Richardson, 1845 from South Victoria Land (Penguin Island, lat. $72^{\circ} \mathrm{S}$.) was treated by Gunther as a synonym of $C$. dorsalis. As Waite $(1906,196)$ remarked, 'If the species be the same, the extremes of latitude, furnish a remarkable instance of geographical range'.

Tasmanian material. Though the writer has collected hundreds of specimens of $A$. mufus and has kept a constant lookout for $A$. dorsalis, he has not himself encountered an example of the latter species. It was therefore a matter of considerable interest to find two specimens in a small collection of $\mathrm{fish}$ made by $\mathrm{Mr}$ B.C. Mollison in southern Tasmania (precise locality not recorded).

Length. With Lt $88.7,91.1$, Ls $87.7,90.0$ the fish reach the size apparently regarded by Johnston as noteworthy, and equal the ' $3 \frac{1}{2}$ inches' of the Handbook.

Dimensions as Tit. Length to origin of dorsal 135, ca 140 (precise origin difficult of determination); of anal 388, 390. Length to vent 384,386 . Head 114, 121; snout 23, 23; eye (heavily pigmented portion, mostly exposed through membrane) 18,18, (total), 23, 23; interorbital 43,40; distance between eyeballs, visible through dorsum 23, 24; distance between anterior nostrils 24, 26. Depth (in parentheses width) at: front of eyes 53 (56), 49 (54); back of eyes 67 (68), 64 (75); gill opening 101 (57), 76 (65); vent 78 (68), 109 (54): maximum, head 101 (77), 77 (77), body 109 (68), 115 (63). Maximum height of dorsal 32,31; of anal 23,23.

Some proportions. Head in $L$ t $8.8,8.3$; in trunk 2.4, 2.3. Length to vent in postvent length 1.6, 1.6. Height in Lt 9.2, 8.7. Eye (total) in head 5.1, 5.2; in snout 1.0, 1.0 ; in interorbital $1.9,1.7$. Length to dorsal origin 7.4 , ca 7.0 ; to anal origin $2.6,2.6$ in $L t$.

Other features Myomeres ca $21+55$. Mouth smal1, cleft nearly horizontal, reaching just to level of (ful1) eye; upper jaw projecting slightly; lips tumid, subequal in width through- 
out most of their length and subequal to each other; tip of maxilla distant from pigmented part of eye by about diameter of latter. Teeth in the jaws in a single series of 10 12 on each side, closely set, forming a continuous ridge throughout most of their height, the briefly projecting tips bluntly pointed; a short almost straight transverse line of several contiguous teeth on vomer. Anterior nostril close to (full) eye at about 10 o'clock (left side viewed); a wide, very short tube, the whole of its outer border continuing as an erect subrectangular flap, whose height equals, or slightly exceeds, basal diameter of tube; internarial subequal to distance of leve1 of insertion of nares behind anterior border of $1 \mathrm{ip.}$. Posterior nostril situated behind, and a trifle mesiad of, anterior, from which it is distant by about half its distance from its fellow; a low simple tube, its elliptical opening transverse, a little oblique, the external end slightly in advance of the internal.

Dorsal originating, rather obscurely, shortly behind head (by less than length of postorbital head); anteriorly a low fleshy ridge; posteriorly, remaining fleshy proximally, but developing a progressively wider distal strip, accounting near tip of tail for about half height of $\mathrm{fin}$, here being thinner, more or less translucent; the external margin almost even throughout, but, as the fjsh lies, with most of the hinder half wavy in the vertical plane. Anal originating almost immediately behind vent (by an eye diameter or less); similar to dorsal, but distinctly lower; margin somewhat crenulate, and, as the fish lies, most of fin wavy in the vertical plane, moderately in (a), slightly in (b). Tip of tail with a continuous, rounded fin line, appearing superficially to be constituted by confluence of dorsal and anal, but seen under a lens to include a small rudimentary caudal with 6-8 short thickish simple rays, not, or barely, extending to border of membrane, their length about $1 \mathrm{~mm}$, subequal to combined anteroposterior extension of last two vertebrae.

Branchial region. The account of the single transverse ventral gill opening and the immediately adjacent region given by Richardson has been somewhat critically discussed by Waite (1906). Some observations on the relevant structures and their interpretation in the present species and in $A$. rufus are included below in notes on the latter.

\section{Alabes rufus (Macleay, 1881)}

ChiZobronchus rufus Macleay, 1881, Proc. Linn. Soc. N.S.W., vi, 2, 266. Type localities, Port Jackson and Tasmania.

Dimensions as TLt. A schedule of dimensions as millesimals of total length similar to that given above for $A$. Corsalis is here provided; based on 5 examples, $: 60,61,63$, 72 , 80, from southern Tasmania (B.C. Mollison). Length to origin of dorsal 326-375, $\bar{x} 346.4 \pm 8.81$; of anal 492-533, $\bar{x} 512.2 \pm 7.09$. Length to vent $361-400, \div 385.0 \pm 6.43$. Head 108-124, $x 116.2 \pm 2.42$; snout $18-31, \bar{x} 23.4 \pm 1.97$; eye (heavily pigmented portion, mostly exposed through membrane) $17-20, \bar{x} 19.0 \pm 1.10$, (tota 1 ) $28-33, x 30.8 \pm 1.09$; interorbital $34-43, \bar{x} 38.2 \pm 1.64$; distance between eyeballs, visible through dorsum 24-30, $\bar{x} 26.20 .91$; distance between anterior nostrils $31-34, \bar{x} 31.8 \pm 0.95$. Depth (in parentheses width) at: front of eyes $42-50, \bar{x} 45.6 \pm 1.19(41-48, \bar{x}+3.4 \pm 1.11)$; back of eyes $62-73, \bar{x} 67.0 \pm 1.94(64-73, \bar{x} 67.0 \pm 1.41) ;$ gill opening $68-95, \bar{x} 78.2$ $4,51(66-73, \bar{x} 69.6 \pm 1.19)$; vent $95-113, \bar{x} 101.6 \pm 3.01(55-67, \bar{x} 6.3 .4 \pm 1.40)$ : maximum, head $70-84, \bar{x} 78.6 \pm 3.01(68-84, \bar{x} 75.2 \pm 2.29)$, body $100-111, \bar{x} 106.6 \pm 2.24(67-75, \bar{x}$ $71.4 \pm 1.20)$. Maximum height of dorsal $26-38, \bar{x} 32.4 \pm 1.71$, of anal $19-26, \bar{x} 22.2 \pm 1.82$. These TLt values exhibit no marked variation from those of A. dorsalis except, of course, in the critical length to dorsal (346.4, cf. ca 138) and length to anal (512.2, $c: 389$ ).

Some proportions. Proportions recorded above for $\dot{A}$. dorsalis are here noted for the present species: they include all those reported by liaite (1906) for his Victorian material (his values in parentheses). Head in $\bar{t} t 8.4-9.2, \bar{x} 8.80 \pm 0.13$ ('eight'); in trunk 2.0-2.6 $\bar{x} 2.25 \pm 0.092(21.3$. Length to vent in postvent length $1.5-1.8, \bar{x} 1.61$ $\pm 0.040(1.5)$. Height in Lt $9.0-10.0, \vec{x} 9.40 \pm 1.58(8.6)$. Eye (tota 1 ) in head $3.3-4.5$, $\bar{x} 3.18 \pm 0.18(3.2)$; in snout $0.6-1.1, \bar{x} 0.79 \pm 0.11$; in interorbital $1.2-1.3, \bar{x} 1.24 \pm$ 


\section{E.0.G. Scott}

0.069 . Length to dorsal origin $2.7-3.1, \bar{x} 2.89 \pm 0.69$; to ana 1 origin $1.9-2.0, \bar{x} 1.96$ \pm 0.024 . For the three ratios involving the eye the coefficients of variation are too great (say, conventionally, 10 ) to have much taxonomic significance, being 13.0, 30.6, 12.5, respectively: coefficients for the remaining ratios are of a satisfactory magnitude, their values being, in order of the non-eye entries above, 3.3, 8.9, 5.5, 4.8, $5.4,2.8$.

Branchial region. Describing the gill opening of Cheilobranchus mufus Richardson (1845, 50) wrote, 'A transverse lip which rises above the surrounding integunent, and has its outer ends free, forms the posterior edge of the orifice, and appears to be capable of closing it very completely when the inflected edge of the membrane is pressed against it'. Commenting on this passage, Waite $(1906,196)$, with examples of $A$. rufus only before him, remarked "This "lip" is present also in C. mfus; it is not a median process as might be inferred, but really a pair of organs which to my eye are nothing but rudimentary pectoral fins. They lie rather low down on the body, some distance apart, close behind, but quite free from the gill membrane, and it is very doubtful if they have any function in connection therewith, as supposed by Richardson.'

It will be noted that Waite appears to assume the branchial region is the same in the two species. This is not quite the case, at any rate in our material. However, the difference lies, not in the existence of different structures, but rather in the degree of development of those present, and an examination of these specimens goes far towards providing a basis for a plausible reconciliation of the two accounts. In $A$. dorsalis (fig. 2) the paired structures regarded by waite (in all probability, correctly; in one individual each appears to have two or three fin rays) as pectoral fins (vestigial, perhaps, rather than rudimentary) are found at the ends of a rather narrow transverse process, with which they are wholly continuous: this bar, which lies immediately in advance of a pillow-like eminence, about half as extensive transversely as the whole apparatus, could well be interpreted as a median 'transverse lip' forming 'the posterior edge of the orifice' and as conceivably being 'capable of closing it very completely'. However, in $A$. mufus (fig. 3) the transverse process, as such, is either undeveloped, or, in some individuals, somewhat doubtfully recognizable as a very narrow fold, its place being usurped by an enlarged median pillow, immediately flanked on either side by the small fans presumed to be degenerate pectorals: as the pillow can reasonably be regarded as being simply a local elevation calling for no express mention, this situation would appear to be compatible with that recognized by Waite.

Mr A.P. Andrews, Curator of Vertebrates, Tasmanian Museum, Hobart, has been good enough to prepare at the writer's request a specimen of $A$. mufus, cleared in potassium hydroxide and stained with alizarin. The pectoral girdle is found to exhibit some interesting evidence of degeneration (fig. 4); the situation, as here provisionally interpreted on the basis of this specimen, being as follows. The cleithrum and supracleithrum together constitute a subelliptical plate,quite the largest element of the system. The posttemporal presents a rather short proximal portion, beyond which it is strongly forked; the pennonlike dorsal prong projecting upwards, outwards, and somewhat backwards, its tip remote from the skull, not possessing, as far as can be seen, any ligamentous connexion with the epiotic region; the ventral prong being angled, with a short forwardly and slightly inwardly directed proximal segment, continued upwards and backwards in a segment about thrice as long, making connexion (ligamentous?) with the skull at, or near, the opisthotic. The two cleithral complexes come into close approximation in the median line, what appear to be the two coracoids (with, perhaps, associated scapulas) being pushed out from between them, closely apposed to form a cruciform unit, lying wholly clear of the cleithra within the bay bounded by the latter bones' posterior borders, from which borders they are distant, at their nearest approach, by rather more than half their own length. A small area of intensified color in the stain at each of the outer ends of the cross may represent a much reduced scapula. Two similar, but smaller, patches detectable at the base (anterior end) of the cross may relate to some other minute, wholly fused element (mesocoracoid?). External to each presumed scapula, and lying free from it at a 
distance of about half their own length or more, are three actinosts, the external one the largest: these lie in a plane a trifle dorsad of that of the scapula, the plane of which is, in turn, somewhat dorsad of that of the cleithra at their internal ends. There are three gill arches, almost equally developed.

Markings. The number of spots along each side is conventionally given as 6-7 (e.g., Macleay, 1881b, Waite, 1906, Scott, 1962); 'with or without 6-7' (Munro, 1957a): we find 0-9. As Waite pointed out, the pattern may not be the same on the two sides. A sample of 37 fish collected between Green's Beach and Kelso, on 8 January 1967 by Mr R.H. Green (Q.V.M. Reg. No. 1972/5/26) gives the following frequency distribution: left side 0 (5 cases), 1 (1), 2 (3), 3 (3), 4 (10), 5 (7), 6(2), 7 (5), 8 (0), 9 (1), total 147; right side 0 (5), 1 (1), 2 (1), $3(8), 4(6), 5(8), 6(4), 7(2), 8(1), 9(1)$, total 146; mean per side $4.0 \pm 4.1$, or, among marked individuals, $4.6 \pm 4.1$. Different counts (greatest difference 2 spots) occur in $16 \mathrm{fish}$. It will be seen that while the totals of the two sides are virtually the same, the modes differ (possibly by mere sampling variation), being 4 on the left side and 3,5 (equal) on the right. Waite's statement that the spots do not extend beyond the origin of the anal is generally, but not invariably, true, the hindmost spot in some individuals being located more than a head length further caudal. Exceptionally, one or two spots (not necessarily collinear with the others) occur on the head.

Vernacular name. The 'Red-banded Shore Eel' of the Tasmanian 1 ists of Johnston, Lord, Lord E Scott, and the 'Red-banded Pigmy Eel' of Munro's Handbook seem decidedly inappropriate, the characteristic markings being well-separated rounded spots, without any suggestion of a band or bands. Shore Eel is used for this species by Scott and for A. dorsalis by Munro. Perhaps a convenient name would be Red-spotted Shore Eel.

\section{Fami1y ANGUILLIDAE}

The two species reported from Tasmania - Anguizla australis Richardson, 1841, (Handbook (Munro, 1957b, 53), A. australis occidentalis Schmidt, 1928), A. reinhardtii Steindachner, 1867 (Handbook, reinhardti) - have been keyed in Part VI $(1953,142)$ [numbered V]. The other species of Anguizla reliably recorded from Austra1ia, A. bicolor McCle11and, 1845, A. obscura Gunther, 1871, do not reach south of Queensland and northwestern Western Australia.

Genus ANGUILLA Shaw, 1803

Anguilla Shaw, 1803, Gen, 2002. (Pisces), IV, 1, 15. Logotype, Muraena anguizla Linné. Anguizla reinharatiz Steindachner, 1867.

Anguizla reinhardtii Steindachner, 1867, Sitab. Akad. Wiss. Wien, 1v, 1, 15, figs a-b. Type locality, Fitzroy River, Rockhampton.

Tasmanian status. The Australian 1ong-finned eel does not appear in either of Johnston's 1ists (1883, 1891), but is treated as Tasmanian by Lord $(1923,1927)$, by Lord \& Scott (1924) and by McCulloch (1929) in the Check list ['Rivers of Eastern Australia (Queensland to Tasmania) ...']. However, in his notable paper on the freshwater eels of Australia Schmidt (1928) express1y states of $A$. reinhardti $i$ 'in Tasmania it has not yet been observed', and the Handbook (Munro 1957b, 53), which is to be regarded as presenting the current conventional view, restricts the [Australian] distribution to Queensland, New South Wales, Victoria.

In a paper (1934), that, by virtue of the appearance of sequent contributions, became in effect Part I of the present series, though not so numbered, notice was taken of three long-finned eels (now apparently lost sight of) exhibited in the Queen Victoria Museum, Launceston because of their size, Lt 1531, 1525, $1635 \mathrm{~mm}$. The Schmidt index $\left[s=\frac{a-d}{t} \times 100\right.$, where $a=$ length to vent, $d=1$ ength to dorsal origin, $t=$ total length $]$ 
reported by Schmidt for $A$. australis ranges from -1.5 to $+4.0, \bar{x} 1.27$, for $A$. reinhardtii from 7.8 to $13.2, \bar{x} 10.7$. Values for the eels mentioned above were 10.8, 11.2, 11.4 . The death of Professor Schmidt in 1933 prevented the completion of an arrangement that was being made for him to examine these specimens. In Part II $(1935,65)$ an example, Lt 1658, S. 13.1, caught near Launceston on 16 April 1934, was reported; while Part VI $(1953,142)$ [numbered V] noted an example, Lt 1671, S 10.7, stabbed to death with a pocket knife in the North Esk at Launceston on 13 August 1937. The latter contribution provides a series of dimensions (table 1) of five large Tasmanian specimens of this species. A large example, not previously recorded, was taken by Mr Blake in the Lake River, a tributary of the Macquarie, in December 1940. Some dimensions (mm); total length 1338; length to dorsa1, anal, vent 457, 600, 574; 1ength of head, snout, eye, pectoral 184, 58, 12, 81; interorbital 46; girth at pectoral base, at vent, maximun $331,391,416$. Weight $10.8 \mathrm{~kg}$. $S=9.1$. Of a considerable number of Tasmanian eels since seen by the writer all, up to the present time, have been $A$. australis.

Flinders Island records. Two large eels from south-east F1inders Island collected on 17 November 1972 (Lt 1333), Q.V.M. Reg. No. 1972/5/747, and 12 December 1972 (Lt 975), Q.V.M. Reg. No. 1973/5/74, by Mr. G.D. Smith are determined as $A$. reinhardtii.

Proportions as TLt. Ls 971, 974 (earlier specimens first). Length to: pectoral origin 135, 154; dorsal origin 336, 354; vent (middle) 431, 466; anal origin 442, 485. Head 138, 154 ; snout 29,31 ; eye $9.8,9.8$; interorbital 37,32 ; mouth cleft 43, 43; anterior internarial 15, 17, posterior internarial 31, 25; , length of pectoral 60, 52; depth at vent 91,76 ; maximum depth 91, 77; girth at dorsal origin 302, 246. S 10.6, 11.2.

Other features. Maxilla to behind eye by $0.6,1.0$ eye. Pectoral 18, 18, short, broad, rounded. Lower jaw exceeds upper by $0.5,0.2$ eye. Larger specimen blackish, almost immaculate; small lighter, profusely spotted, a feature distinguishing this species from A. australis, and a1so from the New Zealand long-finned eel, A. diffenbachii Gray, 1842 (in Schmidt's papers, A. aucklandii Richardson, 1848), regarding which Schmidt observed in 1932 in a letter to the writer 'There seems to be a reason to keep a sharp look out for this species in Tasmania'.

\section{Family APOGONIDAE}

The five species recorded from Tasmania - Dinolestes Zewini (Griffith, 1834), Lovamia fasciata (Shaw, 1790), Siphamia cephalotes (Castelnau, 1875), Vincentia novaeholZandiae (Valenciennes, 1832), Vincentia Zemprièri (Johnston, 1883) - have been keyed in Part XII (1964:99). The specification in the key regarding spines of the second dorsal is an error.

\section{Genus VINCENTIA Castelnau, 1872}

Vincentia Castelnau, 1872, Proc. Zool. Acclim. Soc. Vict., 1, 245. Haplotype, Vincentia waterhousii Castelnau.

\section{Vincentia novaehollondiae (Valenciennes, 1832)}

Apogon novae-hollandiae Valenciennes, 1832, Nouv. Ann. Mus. Hist. Nat. Paris, 1, 55, pl. IV , fig. 2. Type locality, 'Australia' (Quoy \& Gaimard): Check-1ist 'probably $=$ New South Wales'.

Tasmanian status. With Valenciennes' species the Handbook (Munro 1960, 144) synonymizes V. conspersus (Klunzinger, 1872), V. waterhousii Castelnau, 1872, V. guntheri (Castelnau, 1872), V. Zempriem (Johnston, 1883) and V. romsayi (Fowler, 1908), the overal1 range including all Australian States other than Queensland. In Part XII of these Observations (1964, 99, fig. 1) two examples of a Vincentia from Akaroa, near St Helens, identified as Johnston's Apogon lemprieri were described and figured, being regarded as being separable from $V$. novaehozzandiae as characterized in the Handbook by several characters 
discussed below: a third example, also from St Helens, was noticed in Part XVII (1970, 44). The validation of $V$. Zemprieri (type locality, Dunkley's Point, Sandy Bay, Tasmania) as a species distinct from $V$. novaeholzandia (type locality, probably New South Wales) raises the question as to whether the latter is to be regarded as having any standing in the local faunal list.

Tasmanian record. A specimen of $V$. novaehollandiae, Ls 22.5, Lt 29, has now been identified in the collections of the Queen Victoria Museum, Launceston: Reg. No. 1972/ 5/448. It was collected on 28 April 1972 by Messrs R. and Y. Graeme at Clarence Point, Tamar River, being found among seaweed.

Meristic characters. D. VII, I, 8. A. II, 9. P. ii, 11/ii, 12. V.I, 5. L.1. 25. other features. Head 2.4in Ls. Eye 3.1, snout 4.8, interorbita1 3.1, pectoral 1.6, pelvic 1.1, maximum depth 1.1, in head.

Dorsals united. Maxilla to posterior border of pupil. Pectoral and pelvic to second anal spine. Most scales on head or body with microscopic reddish brown punctulations, these not aggregating to form microscopic spots. Indications of some dark coloration on part of first dorsal (membrane imperfect), some dorsal rays dark distally; pelvic dusky in distal half; pectoral and anal more or less colorless, immaculate.

Discussion. Of the four features deployed in the couplet of the 1964 key covering $V$. novaehozzandiae and $V$. Zemprieri perhaps only the first (dorsals united in former, separate in latter) is here significant. Of the others, the second (character of teeth) is probably mainly a question of description; the third (relative length of longest dorsal spine and head) cannot here be employed, the spine being imperfect; while a noticeably greater numerical value $(2.0-2.4$, cf. $1.0-1.1)$ met with in the 1964 material of the latter species was not found to characterize the 1970 individual, in which the value was close to that of unity as in the present fish.

\section{Family SCORPIDAE}

The family Scorpidae (the name is sometimes - e.g. by McCulloch, 1922 - rendered Scorpididae) is recognized by most authors; however, in the provisional classification of living teleosts of Greenwood et al. (1966) Scorpidae (Scorpididae) is subsumed, along with Parascorpididae and Girellidae, in Kyphosidae (Cyphosidae).

Only one member of the Scorpidae, s.s., Scorpis georgiconus Valenciennes, 1822 , is credited to Tasmanian in the Check 1ist (NcCu110ch 1929). However, the local list now comprises four species, $S$. aequipinnis Richardson, 1848 , having been recorded from near George Town, Dorset in Part II of these observations $(1935,67)$ and $S$. lineolatus Kner, 1865 from Swimcart Beach, near St Helens, Dorset in Part XVII $(1970,45)$, while Atypichthys stmigatus (Günther, 1860) is here reported from George Bay, Cornwall/Dorset.

For a key to the three Tasmanian species of Scorpis Valenciennes, 1822 reference may be made to Part XVII. Atypichthys strigatus may be distinguished from the keyed species thus:

Dorsal spines $I X-X$; dorsal rays, anal rays each> 20 (ca 23-28); highest dorsal spine lower than highest dorsal ray; color markings dark vertical bars, or dark spots, or none - Tasmanian species of Scompis. Dorsal spines XI-XII; dorsal rays, anal rays each <20 (ca 15-16); highest dorsal spine higher than highesi dorsal ray; color markings iongitudinal (6-8 brown stripes) - Atypichthys strigatus.

\section{Genus ATYPICHTHYS Gunther, 1862}

Atypichthys Günther, 1862, Cat. Fish. Brit. Mus., 4, 510. Nom. nov. pro Atypus Günther, 1860, preocc. in Arachnida. Haplotype Atypus strigatus Günther, 1860. 


\section{Atypichthys strigatus (Gunther, 1860)}

Atypus strigatus Günther, 1860, Cat. Fish. Brit. Mus., 2, 64 and 518. Type 1oca1ities, Swan River, W. Australia; Holdfast Bay, S. Australia; Raoul Is.; Erromanga, New Hebrides. Atypichthys mado whitley, 1931, Aust. Zool., 6, 4, 319. Type locality, Manley, New South Wales.

Tasmanian record. Three examples, 102-110 in standard length, were collected by $\mathrm{Mr}$ K.J. Atherton in George Bay, on 14 January 1973 (Q.V.M. Reg. No. 1973/5/29). In the same month the mado was reported by scuba divers also from Stony Head, Dorset, and Clarke Island, Furneaux Group, Bass Strait.

Distribution and status. The Check-list distribution is Queensland, New South Wales, Western Australia, South Australia, New Zealand, Western Pacific. Whitley (1931, 319) observed of Günther's description it 'appears to be a compound one based on specimens, probably not conspecific, from diverse localities'; and designated Raoul Island, Kermadec Group, as the type locality of A. strigatus. He then proposed a specimen from Manley, New South wales as holotype of a new species, $A$. mado, 'the Peronian representative of $A$. strigatus'. In a later publication $(1962,157$ ) the entry for $A$. mado (with Steindachner's figure) gives its distribution as 'Q'ld and N.S.W. With close relatives from W.A. to New Zealand and some south-western Pacific Islands'; and A. strigatus appears formally in the New Zealand check-list (Whitley, 1968,61). As a further complication, it is to be noted that though South Australia appears among the type localities of Günthers materia1, Scott $(1962,223)$ observes that the record for that state is 'extremely doubtful'. It would thus appear the reported patterns of distribution provide no clear pointer to the identity of the Tasmanian fish, if, indeed, $A$. strigatus and $A$. mado are distinct. Morphologically, the latter is noted as differentiated from the former on $1 y$ by 'the sma11 scales'. Günther's material is reported as having 1.1.70-75, 1. tr. 11/26: our values are 70-78, 11-12/24-26 - there thus appears to be no morphological ground for distinguishing the Tasmanian fish from $S$. strigatus.

Length. Is (a) 102.1, (b) 104.5, (c) 110.2. Lt, upper lobe, lower 1obe of cauda 138.5 ,

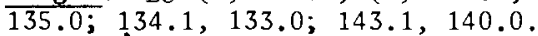

Meristic characters. D. XI, 16; XI, 16; XII, 16 (first spine minute (1.2mm), wholly detached from rest of fin). A. III, 16; III, 17; III, 17. P. 1,15 (1eft)/1,15 (right); $2,15 / 1,15 ; 2,15 / 1,16$. V.I, 5. C. $10+8 ; 10+8 ; 9+9$. L. $1.70 ; 75 ; 78$. L. tr. $11 / 26$; $12 / 24 ; 12 / 25$.

Some dimensions as TLs. Length to origin, termination of first dorsal (spine-spine) 326,676; 331, 660; 336 (normal spine), 700: of second dorsal (ray-ray) 734, 911; 717, $863 ; 757,883$ : of anal 593,$917 ; 573,883 ; 623,871$. Pectora1: 1ength to origin, 1ength of fin, length of longest (4th) ray 264,273,246;249,242,230; 263,263, 235. Ventral: length to origin, length of fin, length of longest ray (next to spine) 354, 222, 211; $325,208,187 ; 297,193,190$. Length to vent, front, back 552, 562; 535, 568; 564, 599. Head $293 ; 278 ; 272$. Snout $66.6 ; 67.0 ; 64.4$. Eye 97.9;94.7;91.7. Interorbita1 101; $98.6 ; 95.3$. Depth at front of eye $157 ; 163 ; 150$ : at back of eye $289 ; 292 ; 288$ : at opercular border 411; 392; 404: at first dorsal origin 470; 440; 454: at middle of vent 470; 440; 386: at caudal peduncle (minimum) $118 ; 118 ; 109$ : maximum depth 495; 459;481. Dorsal rays: first, longest, last $96.0,116,76.4 ; 90.0,105,77.5 ; 80.8,101,72.6$. Anal rays: first, longest, last $89.1,105,71.5 ; 95.7,106,67.9 ; 91.6,92.6,66.2$.

Dorsal spine pattern. For a general discussion of these interesting spine and ray length - number patterns, together with notation conventions, see Part XIX (1974). The minute supernumerary spine of specimen (c) in advance of, and wholly detached from, the rest of the fin is not included in the pattern specified below. $D=D_{1} D_{2} D_{1} D_{2}$
$=\emptyset$. For each specimen there is given below: first, a tabulation of the members of the subset; secondly, the equation for the regression of $L$ (length of spine, mm) on $N$ or $N^{1}$ 
(serial number of spine counted caudad, or counted cephalad); third1y, $t$; fourth1y, spine lengths (m) calculated from the equation (in parentheses measured lengths).

(a) $D_{1}=x / x=I-V I: \log L=0.4686 \log N+0.9081: t=41.081: 8.1$ (8.1), $11.2(11.0), 13.5(13.9), 15.5(15.6), 17.2(17.1), 18.7(18.6) . D_{2}=x / x=$ VII-XI: $\log L=0.3652 \log N+0.9752: t=9.706: 9.4(9.5), 12.2(12.1), 14.1(13.9), 15.7$ $(15.9), 17.0(17.0)$.

(b) $D_{1}=x / x=I-V: \log L=0.4737 N+0.9048: t=40.530: 8.0(8.0), 11.2$ $(11.1), 13.5(13.8), 15.5(15.5), 17.2(17.0) . D_{2}=x / x=$ VI-XI; but VI imperfect, calculated VII-XI': $\log L=0.3277 \log N+0.9589: t=5.833: 9.1(9.1), 11.4(11.1)$, $13.0(13.0), 14.3(14.0), 15.4(15.5)$.

(c) $D_{1}=x / x=I-I V: \log L=0.6483 \log N+0.8534: t=4.241: 7.1$ (7.P), $11.2(11.0), 14.6(14.8), 17.6(18.0)$. $D_{2}=x / x \mathrm{~V}-\mathrm{XI}: \log L=0.316410 \mathrm{l} N+$ $0.9638: t=27.695: 9.2(9.0), 11.5(11.8), 13.0(13.3), 14.3(14.0), 15.3(15.3)$, $16.2(16.1), 17.0(17.0)$.

Note there is not here, as there is in most species so far examined, a unique serial number for the largest member of $D$, the number of elements of $D$, ranging from 6 to 4 , decreasing (?functionally,? adventitiously) with increasing size of specimen. of the four sets of parameters of the equations for the three specimens, the coefficienf of $\log N$ and the independent term of $D_{1}$ vary directly, and the coefficient of $\log N$ inversely, with length of fish; but ${ }^{1}$ the sequence in decreasing magnitude of the independent term of $D_{2}$ is (a), (b), (c). None of the three correlations is statistically significant: however, their group existence, especially when considered in conjunction with the occurrence in other fins (see below) of comparable sequences, would seem to indicate the relation is a genuine one.

Anal spine pattern. $A=x / x=$ I, III, II. In the species first investigated the logarithmic lengths of anal spines I, II, III were found to be a linear function of the logarithms of $1,2,3$, respectively (slope positive). Here the second spine is the longest. However, $\log$ lengths of such a series (I, III, II) on $\operatorname{logs} 1,2,3$, respectively, are significantly collinear. This relation has been found to hold also in other species with $m=I I$. To supplement $H, W$, already in use, denoting serial number in a set, counting caudad (in unpaired fins; in paired fins 'onwards', by prescribed conventions) cephalad, respectively, $N A$ is here introduced (' $A$ ' from 'arbitrary') to denote a series of positional numbers arranged in a special sequence.

(a) $\log L=0.3868 \log N^{\mathrm{A}}+1.0235: t=23.101 .10 .5(10.5) \cdot 13.8(14.0) \cdot 16.1$ $(16.0)$.

(b) $\log L=0.3991 \log N^{A}+1.0012: t=11.709 .10 .0(10.1), 13.2(12.9), 15.4$

(c) $\log L=0.4055 \log \eta^{\mathrm{A}}+0.9991: t=8.174 .10 .0(10.1), 13.2(12.8), 15.6$ $(15.9)$.

Ventral ray and spine pattern. In the ventral fin of some species examined, in which the longest ray, $m$, is the 4 th (counting outwards towards spine), the pattern found is $v V .=$ $\mathrm{v}_{1} \mathrm{U} \mathrm{v}_{2} \mathrm{~V}$; with $v_{1}=x / x=1-4 \quad \mathrm{v}_{2} \mathrm{~V} \quad x / x=4,5, \mathrm{I}$ (spine) $=m-$ the spine being plotted on $\log 10$, an ad hoc procedure lacking any obvious significance, but in practice commonly yielding a significant best straight line for the mixed three elements. In the present species, in which the longest ray is the 5 th, the formulation that best fits the data is $\mathrm{v}=x / x=3-5$ [descending] $\mathrm{v}_{2} \mathrm{~V}=x / x=1,2$, I [ascending] $=\emptyset$.

$\underline{\mathrm{u}}_{1}$ (a) $\log L=-0.1645 \log { }^{1}+1.3232: t=20.629: 21.0(21.0), 18.8(18.5), 17.6(17.5)$.

(b) $\log L=-0.1776 \log N^{1}+1.3031: t=8.706: 21.0(20.0), 17.8(18.0), 16.5$ (16.4).

(c) $\log I^{\prime}=-0.2054 \log N^{1}+1.3332: t=7.609: 21.5(21.4), 18.7(19.0), 17.2(17.0)$. 
$\begin{aligned} \underline{\mathrm{u}}_{2}, \underline{\mathrm{V}} \text { (a) } \log L & =0.1625 \log N^{\mathrm{A}}+1.0944: t=14.023: 12.4(12.4), 13.9(14.0), 14.7(14.8) . \\ \text { (b) } \log L & =0.1013 \log N^{\mathrm{A}}+1.1152: t=8.170: 13.0(13.0), 14.0(14.1), 14.6(14.5) . \\ \text { (c) } \log L & =0.1379 \log N^{\mathrm{A}}+1.1107: t=16.333: 12.9(12.9), 14.2(14.2), 15.0(15.0) .\end{aligned}$

Non-metrical features. Jaws equal anteriorly. Mouth to 0.5 eye (all individuals). Width of maxilla subequal to its direct distance from eye. Preorbital dentate. Preoperculum strongly spinulate. Posterior nostril set obliquely downward and forward, about twice size of anterior, from which it is distant as far as from eye or a little less. Interorbital strongly convex. Pectoral extending 0.9 (all specimens) of distance to vent; ventral to anal origin, midway between vent and anal origin, end of vent. Scaly sheath on dorsal rays and anal rays, not on spines of either fin; compact, extending up at least $4 / 5$ of the lengths of the rays, only the branched tips of these delicately projecting. The extensive development of sheath in the anal here contrasts strongly with the quite narrow basal strip in Steindachner's figure (in which, as far as can be judged from reproductions of the figure in local texts, the dorsal rays also appear to be traceable throughout most of their length, unhidden by any sheath). First anal spine attached by membrane to basal $1 / 5,1 / 4,1 / 5$ of second, which is attached to basal - (damaged), $\frac{1}{2}, \frac{1}{2}$ of third, which is attached from its basa1 2/3, 19/20, 5/6 to first ray.

Coloration. Ground color yellowish or whitish, becoming lighter and somewhat more silvery on lower part of lateral surface; ventral surface approximating white. Characteristically with 7 strongly-marked well-delimited longitudinal stripes of dark brown: first (uppermost) stripe narrow, curved, constituting dorsal profile between level of mouth and first one-fifth or so of second dorsal; in (a) extending, as a continuous line, on to second dorsal from its base anteriorly to near its distal margin posteriorly; in (b), (c) variably represented on fin on the right and left sides, continuous, or in one line plus one or two short streaks, or, on right side of (c), in two subparallel streaks, outer about half as long as inner: second, broadest, curved (convex dorsad), continuous from level of back of eye to end of second dorsal base, on to which it extends: third, nearly as broad, its width about twice interspace between second and third or interspace between itself and fourth, almost straight, from middle of eye to upper border of caudal peduncle, on to which its lower half extends: fourth, somewhat narrower than third, straight, from before eye to upper half of caudal peduncle, its lower border on caudal peduncle coincident with lateral line there; fifth, narrower, straight, from middle of posterior border of orbit on to lower one-third of caudal peduncle, where it becomes more slender, fainter: sixth, narrower still, about half, or less, interspace between itself and fifth, straight, from upper insertion of pectoral, petering out shortly in front of anal termination: seventh, narrowest, least intense, almost straight, from a little behind head, traceable to near hind half of anal, virtually obsolete in (c). The anterior courses of the second and third stripes vary from fish to fish, even somewhat from side to side: in the most regular, presumably 'normal' pattern, as found in (b), the right and left second stripes join immediately in front of the first dorsal origin, embracing it in a neat $V$, while the two third stripes converge above the eyes, and then run forward parallel, separate by less than width of one stripe, to tip of snout, meeting here a pronounced blackish transverse arc outlining upper lip; in (a) and (c) the arrangement is much less symmetrical, noteworthy variations including some interruption to the third stripe, and the extension forward of dorsal origin of the second, with or without its becoming confluent with the third. The size and disposition of the longitudinal bands in our material are in good overall agreement with those of the bands in Steindachner's figure of A. strigatus, reproduced in Whitley (1962, 157) in illustration of $A$. mado Whitley, 1931. Minor variations (other than those of mere intensity in the lower one or two stripes): sixth begins near upper (in figure, lower) insertion of pectoral, general course of those near middle of series somewhat more nearly rectilinear.

First dorsal membrane probably originally yellow, heavily punctulated with brown, between some (possibly originally, most) spines an oblique dark stripe extending from 
near base of one spine to near point of attachment of membrane to next spine (in Steindachner's figure these markings appear as light lines). Second dorsal yellow and yellowish distally, brownish, yellowish or whitish proximally; marked with brown as described above. Anal sheath sulphur yellow in two fish, less bright yellow in other; some dark microscopic punctulation, variable in extent and intensity in specimens and on sides of same specimen; projecting tips of rays whitish; membrane between spines yellowish, with or without dark peppering; spines where exposed colorless. Pectoral chiefly whitish with some (probably originally considerably more) yellowish proximally. Ventral in (b) whitish; in others white in basal half or so, dusky distally. Caudal to end of middle rays and on lateral rays to beyond this level, the area being demarcated by an oblique backwardly convex arc, almost uniform yellowish, with some rather faint and imperfect narrow dusky lines, outlining rays; beyond this, wholly white in (b), (c), in (a) white with some duskiness along part of ventral border of inferior lobe.

$$
\text { Genus SCORPIS Valenciennes, } 1832
$$

Scompis Valenciennes, 1832, in Cuvier \& Valenciennes Hist. Nat. Poiss., VIII, [']831'= 1832], 503. Haplotype, Scorpis georgianus Valenciennes.

\section{Scomis Zineolatus Kner, 1865}

Scorpis Zineolatus Kner, 1865, Reise Novara, Zool., 1, Fische, 1, 108, pl. v, fig. 3. Type locality, Sydney.

Additional records. The inclusion in the Tasmanian list of this species is based on a record in Part XVII $(1970,46)$ of 7 juveniles taken at Swimcart Beach on 5 May 1968. Additional records: (a) $L s 167$, Lt 228 , length to middle caudal rays 188 , about $3 \mathrm{~km}$ east of Wynyard, 17 June 1972 George Bay (scuba dive; G. Reardon); (b) Ls 115, Lt 152, length to middle candal rays 132 , George Bay, 14 January 1973, K. L. Atherton, Q.V.M. Reg. No. 1973/5/24. The locality of (b) is within less than $10 \mathrm{~km}$ of that of the 1968 material: specimen (a) provides the first formal record for our northern coast. Specimen (a) has D. X, 27, A. III, 27; (b) D. X, 26, A. III, 28.

Dorsal and anal spine patterns. The anal spine pattern has been determined for both examples, the dorsal spine pattern for (a) only, some spines being imperfect in (b).

D. $\log \bar{\Sigma}=1.5402 \log \eta+0.6946$. Spine lengths as measured (in parentheses as estimated from the regression equation): $5.0(5.0), 7.0(7.2), 8.7(9.0), 10.9(10.5)$, $12.0(11.8), 13.0(13.0), 14.0(14.2), 15.3(15.2), 16.4(16.2), 17.0(17.2) . \div=24.95$.

A. Specimen (a). $\log L=-.4743 \log \because+0.6946$. Lengths: $10.4(10.4), 14.5$ (14.6), $17.5(17.5) . t=185.56$. Specimen (b). Log $\underset{\sim}{\sim}=0.3572 \log i+0.9002$. Lengths: 8.0 $(7.9), 10.0(10.4), 11.9(11.8) . t=12.68\left[z_{0.05} t=12.71\right]$.

Frequency of occurrence. This species is perhaps more abundant here than has hitherto been thought. While $S$. georgianus is readily distinguishable from the two other species in having the soft dorsal and the anal rather strongly produced anteriorly and (normally) in being marked with some four or five dark vertical bars, the distinction between $S$. aequipinnis and $S$. Zineolatus, both with soft dorsal and anal rather slightly or barely produced anteriorly, and (normally) lacking dark bars, is not so immediately obvious, and it is probably the two latter species have at times been confused in records of catches at scuba dives. A satisfactory determination can be made by use of the key provided in Part XVII: however, a simple criterion, readily applicable in the field, is the following - in S. aequipinnis the greatest width of the expanded posterior end of the maxilla is subequal to, in $S$. lineolatus greater than (usually about twice), direct distance of maxilla from eye. 


\section{Fami1Y URANOSCOPIDAE}

Two species are credited to Tasmania in the Gheck-Iist: Kathetostoma Zaeve (Bloch \& Schneider, 1801), Genyagnus monopterygius (Bloch \& Schneider, 1801). The former, known from a11 Australian States except Queensland, occurs in all Tasmanian lists from the earliest, that of Johnston $(1883,115)$, who notes its inclusion in the unpublished catalogue of Allport; it is not uncommon in our waters. The latter, the distribution of which is given in the Check-list as Tasmania, New Zealand, Tahiti?, does not appear in any local list; no Tasmanian examples have come under the writer's notice. Two species occurring in South Australia that it would not be wholly surprising to encounter here are Kathetostoma nigrofasciatus Waite \& McCulloch, 1915, Ichthyscopus barbatus Mees, 1960. A Kathetostoma identified as K. giganteum Haast, 1873, a New Zealand form, is here reported from Coles Bay, Glamorgan, the first record from Australian waters: the determination is based on criteria given by Waite \& McCulloch (1915), rather than on those of Haast's original account.

Key to Uranoscopidae Recorded from Tasmania

1 No spines on preoperculum, on mandible, or in front of ventral fin ..........

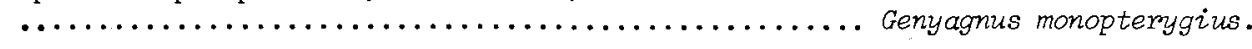

On each side of fish, three spines on lower margin of preoperculum; one on lower portion of mandibular ramus, one in front of each ventral fin ......... 2 .

2 fHead and body with broad dark cross bars; not, or faintly and unextensively, marbled. A dark blotch on preoperculum. No white streak along lateral 1 ine. (No white

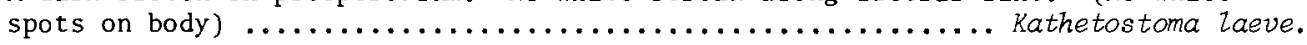

LHead and body without broad dark cross bars; heavily and extensively marbled. No dark blotch on preoperculum. A white streak along latera1 line. (In our specimen, white spots on body) $\ldots \ldots \ldots \ldots \ldots \ldots \ldots \ldots \ldots \ldots \ldots \ldots \ldots \ldots \ldots$ Kathetostoma gigantewn.

Genus KATHETOSTOMA Günther, 1870

Kathetostoma Günther, 1870, Cat. Fish. Brit. Mus., II, 231. Haplotype, Uranoscopus Zaeve Bloch \& Schneider.

\section{Kathetostoma Zaeve (Bloch \& Schneider, 1801)}

Uranoscopus Zaeve Bloch \& Schneider, 1801, Syst. Ichth., 47, p1. VİII. Type 1ocality, New Holland (Latham) $=$ New South Wales (fide McCulloch 19\%, 335).

Material. All in collections of Queen Victoria Museum, Launceston. (a) Ls 474, Preservation Bay, $6 \mathrm{~km}$ west of Burnie, 1 November 1940 (W.J. Beaumont; in seine net), Q.V.M., Reg. No. 1940.2; (b) Ls 246, Rowel1a, River Tamar, 27 February 1941 (T. Hinds; netted), Reg. No. 1941.91 (stomach contents noted in Part $V(1941,51)$; (c) Ls 439, Boat Harbour, 21 February 1950 (A.G. White), Reg. No. 1972/5/661; (d) Ls 392, West Arm, River Tamar, (Cannon), Reg. No. 1941.55; (f) Ls 370, Lefroy, near Currie River, 11 February 1963 (L. McGowan), Reg. No. 1963/5/1; (g) Ls 371, Sandy Beach, River Tamar, 9 January 1966 (M. Wells), Reg. No. 1972/5/660; (h) Ls 166, Tam-o'-Shanter Bay, 15 May 1968 (J.W. Room); Reg. No. 1968/5/22; (i) Ls 197, Table Cape, 20 December 1969, (Morrison), Reg. No. 1969/5/33; (j) Ls 111, Coles Bay, 7 April 1975 (E. Scott), Reg. No. $1973 / 5 / 90$.

Meristic characters. Few quantitative data for this species are available. Meristic observations and measurements of the 10 individuals listed above, made in the course of their comparison with the specimen of $K$. giganteum discussed below, are here recorded. D. 13 (1 specimen), 14 (9). A. 13 (1), 14 (6), 15 (3). P. 18 (7), 19 (2), 20 (1). V.I, 5. C. 9 main rays reaching hind border $+(1+1)$ shorter rays. 
Proportions as TLS. For each dimension there are given range, mean with standard error, coefficient of variation, and, in parentheses, the value for our example of $\mathrm{K} \cdot \mathrm{giganteum}$. 'Length to' measurements are taken from most advanced point, tip of chin.

Length to origin, termination of dorsal 523-600, $567.7 \pm 5.76,3.2(611), 876-$ $964,912.6 \pm 7.08,2.5(927)$; of anal $512-584,552.1 \pm 3.21,1.8(581), 905-973,943.1$ \pm 5.80 (927). Length to origin of pectora1 190-229,208.2 $\pm 3.55,5.4(193)$; 1ength of fin $387-446,419.7 \pm 5.19,3.9(386)$. Length to origin of ventral, at anterior border of gird1e 46-69, 58.7 $\pm 1.81,9.8$ (57), at insertion of spine 96-127, 105.3 $\pm 2.99,9.0$ (95); length of fin, from anterior border of girdle 244-301, 280.2 $\pm 5.43,6.1$ (282), from insertion of spine 183-253, 229.2 $\pm 5.76,7.9$ (186). Length of caudal 205-283, $231.1 \pm 7.72,10.6$ (234). Length to vent (midd1e) $484-529,502.1 \pm 4.64,2.9$ (541).

Head, to hind border of operculum $283-351,319.8 \pm 6.28,6.2$ (294), to midpoint on hind border of armature 241-270, 253.7 $\pm 5.14,6.4$ (259). Length to base of humeral spine 380-441,399.3 $46.20,4.9$ (389). Eye, with fleshy rim $28-46,34.4 \pm 1.73,15.9$ (41), without $\operatorname{rim} 24-42,31.0 \pm 1.76,22.6$ (38). Bony orbit, between midpoints of anterior and posterior borders $37-61,45.4 \pm 1.91,13.3$ (46), between midpoints of lateral borders 34-59, 40.9 $\pm 2.35,18.2$ (48). Interocular 100-125, 113.3 $\pm 1.79,5.0$ (98): interorbital (bony) $90-117,102.3 \pm 2.39,7.4$ (95). Snout, from tip of upper jaw 24-43, $32.4 \pm 2.09,20.5$ (25), from most advanced point (tip of chin) 75-103,84.8 $\pm 3.19,9.5$ (79); the latter origin in advance of the former by $43-66,56.6 \pm 2.53,14.1$ (51).

Depth, maximum $202-259,217.7 \pm 5.14,7.5$ (228), at vent $193-237,209.4 \pm 4.12$, 6.2 (209), at caudal peduncle $82-104,90.3 \pm 1.90,6.7$ (87). Width, maximum 345-408, $379.7 \pm 6.32,5.3$ (364), at front of eyes $189-264,239.3 \pm 6.82,9.0(209)$, at back of eyes $284-314,299.7 \pm 3.03(275)$, at vent $233-314,273.2 \pm 9.45,10.9(225)$.

For the 31 ratios 1 isted the distribution of the number of entries lying within the range $\bar{x} \pm \theta$ is 5 ( 5 cases), 6 (9), 7 (8), 8 (7), 9 (2), with a mean of 6.74 (cf. the theoretical value in an infinite population with the normal distribution, 6.83 ).

Variation with size. While statistically significant correlations between TLs values of sectional neasurements and $L s$ are in general hardly to be looked for in a small tolerably variable sample such as the present, one such case may be noted, that of snout length from most advanced point of fish $\left(r=+0.78, z=1.03, t^{* *}=3.95\right)$. It is pertinent also to point out that with the series divided into two groups constituted by the smallest 5 and the largest 5 individuals higher mean values of the latter are regularly found for all (3) depth and all (4) width entries, and lower values for all (6) measurements involving eye or orbit.

Cranial armature. Some observations on the nature of the actual sculpturing are made below in the account of $K$. giganterm.

In contrasting their $K$. nigrofasciatum with $K$. laeve Waite $\xi$ McCulloch state that whereas the hind margin of the cranial plate in the former is 'interrupted by two backward projections', in the latter it is 'nearly straight', features clearly seen in their illustration. Outline figures in Scott $(1962,235)$ of three uranoscopids show, for $K$. Zaeve, this margin as being in the general sense straight, with two sha1low lateral bays, flanking a median segment itself exhibiting two very slight dips. While the margin in this species is certainly clearly distinguishable from that of $K$. nigrofasciatum, lacking the two pronounced backward processes, it is in our material by no means as straight as in the figures of Waite $\&$ McCulloch and Scott, most specimens exhibiting some degree of sinuosity, normally more or less bilaterally symetrical on either side of a variably developed median proconvexity, and presenting, overal1, a we11 marked forwardly directed arc. Considerable variation in detail occurs; and an occasional individual bears supernumerary ossifications in the form of scattered islets lying a little behind the main plate. 
Lateral line. In some individuals the lateral line is traceable with difficulty; where clearly developed it is commonly much as figured by waite \& McCulloch (pl. XIII, fig. 1) for $K$. nigrofasciatum (there does not appear to be an available figure for $K$. Zaeve), though the pores are sometimes more numerous. Occasionally short closely set ridges, with length up to an eye diameter or more, are developed along the main longitudinal ridge, from which they project outwards and backwards (a few al so may project inwards). They are closely beset by, and sometimes perforated by, the pores: in specimen (g) there are 60 (left), 51 (right) such offsets to the point on the caudal peduncle at which the lateral line turns briefly downward, the succeeding segment bearing 10 offsets, followed by 7 large perforations extending well on to base of caudal.

For course of lateral line, see observations on $K$. giganteum below.

Kathe tostoma giganteum Haast, 1873

Kathetostoma giganteum Haast, 1873, Trans. N.Z. Inst., V. 274, pl. XVI, fig. 2. Type locality, Heathcote estuary, near Sumner, N.Z.

Material. A Kathetostoma, Ls 316, Lt 390, in the collection of the Queen Victoria Museum, Launceston, Reg. No. 1972/5/617, netted at Coles Bay on 6 November 1972 by Mr R. Standage is strikingly different from a11 specimens of Kathetostoma Zaeve examined. It is here determined, somewhat provisionally, as $K$. gigantewm Haast, 1873 , not hitherto reported from Australian waters.

Meristic features. D. 17. A. 16. P. 20. V.I,5. C. $9+(1+1)$.

Proportions. A set of 31 proportions as TLs has been included, for typographical economy, with the corresponding data for $K$. Laeve, above. Additional TLS measurements of fin rays: longest ( $4 \mathrm{th}$ ) dorsal 139; longest (14th) anal 120; longest 'free' pectoral ( 9 th from below) 318, longest (11th) pectoral 322, uppermost pectoral 282; pelvic, in succession from innermost, 204, 212, 182, 138, 98, spine 63.

Coloration. This is strikingly different from that of $K$. Zaeve or of $K$. nigrofasciatum.

(a) Trunk. Dorsal surface in advance of dorsal fin predominantly bluish, (this blue color, however, is due to a superficial, possibly adipose film, removal of which reveals a ground coloration beneath similar to that behind level of dorsal origin); five whitish and five smaller blackish blotches, nearly a score of clearly delimited mostly round white spots, modally about $2 \mathrm{~mm}$, a sprinkling of smaller ones; behind dorsal origin whitish ground, heavily mottled and maculated with brownish and bluish brown, the irregular markings mostly 1-7 mm, on right side only two small white spots. Lateral surface for short distance behind head with downward extension of the bluish from anterior dorsum; rest, in general, resembling dorsum behind dorsal origin; mottlings constituting an overall dark area, about $30 \times 20 \mathrm{~mm}$, below dorsal fin, in advance of this smaller, less compact, behind even more so; markings extending down about half depth of flank anteriorly, about two-thirds on caudal peduncle, becoming less extensive, less intensive ventrad. A white streak along the whole length of the lateral line. Ventral surface behind level of pectoral wholly whitish; rest to level of front of pelvic girdle evenly dusky, save for small whitish patch, about $15 \times 20$, behind pelvic insertion.

(b) Head. Armored region mainly light brownish, with some black spots and short dashes. Laterad of armor, continuing down nearly to ventral profile, like most of side of trunk; soft interorbital area dark bluish brown with transverse arc of off-white; no dark patch on operculum or preoperculum; frontal aspect slaty in upper half, whitish in lower half with some bluish brown splashes. Upper lip mainly bluish brown and brown, a very narrow white anterior border, lower lip with more brown. Inside of mouth white or whitish; tongue dead white. 
(c) Fins. Dorsal membrane greyish; an imperfect narrow border of whitish; dusky along distal one-fourth of first half dozen rays; dark bar or splash between outer parts of some rays; free tips of rays yellowish. Anal membrane mostly concolorous with adjacent flank; a dusky area beneath last half dozen rays; stout free tips of rays conspicuously white (on right three rays, on left one, with basal black mark). Pectoral with proximal two-thirds or so, except near upper and lower borders, darkish grey, spotted with darker; borders of basal portion and, except for a wide irregular marginal band of whitish, all distal portion darker, about concolorous with proximal spots; stout free tips of lower rays conspicuously white; internal surface of fin much like external: base of left fin with upper half smooth, white, immaculate, lower half deep greyish; of right fin mostly whitish, upper one-third with a few, rest with a good many, darkish spots. Caudal greyish, with scattered darker patches, several nearly black; most of uppermost ray, much of lowermost, dark, in part black; a subterminal arc of about a score of short (about $5 \mathrm{~mm}$ ) subrectangular dark markings, some on rays, some on membrane; a light terminal band (3-5 wide) across whole border, membrane whitish, rays pale somewhat greenish yellow.

Discussion. In general structure and proportions this fish agrees closely with $K$. Zaeve as that species is represented by our material: it differs strikingly from it in color pattern, and, less notably, in some other features. In their account of $k$. nigrofasciatum Waite \& McCulloch state their species, K. Zaeve and $K$. giganteum can be satisfactorily identified by a key based solely on color pattern (one criterion for K. giganteum, 'a white stripe along the lateral line' is not noticed in Haast's original description). By this key the present fish clearly comes out as $K$. giganteum.

There are, however, several difficulties. Haast's figure (an outline sketch) shows the anal as beginning behind, and having a shorter base than, the dorsal: in $K$. Zaeve, $K$. nigrofasciatum and the present specimen the anal begins in front of the dorsal and has the longer base. The dorsal, anal and pectoral counts of the Coles Bay specimen do not agree in toto with the counts for K. giganteum (D.16:A.16:P.22; Haast), the counts for K. Zaeve (D., our material 13-14, Scott $(1962,17)$ 15-16, early writers (e.g., Macleay, 1881a, 562; Johnston, 1891, 33) 17: A. 13-14, 15-16, 17, respectively: P. 18-20, 15-16, respectively), the counts for $K$. nigrofasciatum (D. 13-14: A. 13-14: P. 19 (Scott), in part extending the typical 14, 14, 19). It may be observed that on the basis of dorsal count our specimens of $K$. Zaeve would be referable, according to the key by Scott (1962: 245 ), to $K$. nigrofasciatum.

According to Waite \& McCulloch, the exposed cranial bones are sculptured into reticulating ridges in $K$. Laeve, and into tubercles in $K$. nigrofasciatum, while in $k$. giganteum ('head partly rugose and covered with numerous grains', Haast) the sculpture is granular. No example of $K$. nigrofasciatum is at hand. However, any suggestion that the sculpturing in $K$. Zaeve consists wholly of reticulating ridges is not borne out by our material, which presents a variety of elevations reasonably describable as ridges (separate and confluent), tubercles and grains; the first being the most abundant. Hence it is not possible to draw, on the basis of nature of relief, an absolute line of demarcation between $K$. Zaeve as found and $K$. nigrofasciatw as described. However, in the Coles Bay fish, while some elevated lines are present in the main (postocular) cephalic plate (trenchant ridges occur in the preorbital in all species), the modal relief element is a boss rather than a ridge, making feasible a quantitative, if not a strictly qualitative, distinction from $K$. Laeve.

The distinction between the two species is aided by the starlike formations noted by Haast. The most conspicuous of these are two paired sets of lines, constituted chiefly of grains, radiating, on each side of head, one from a point shortly behind posterointernal projection of bony orbit, the other from a point almost directly behind this near the hind border of the armor, the transverse distance between members of each pair being rather greater than the anteroposterior interval between pairs. On each side the radiations from the two centres together form a figure resembling a karyokinetic spindle. The inner halves of the two spindles occupy most of a somewhat depressed rectangular region lying behind the smooth unarmored interorbital space. In $K$. Zaeve somewhat similarly 
disposed striae, more or less regularly directed outwards from the centre of this rectangle, are often traceable; but the spindle elements outside the rectangle are not recognizable. In the Coles Bay fish there occur, on each side, two other, less conspicuous, less extensive systems of radiating lines of bosses, one with centre just laterad of the posteroexternal angle of bony orbit, the other behind and somewhat laterad of the first, close to hind border of cephalic plate.

\section{Family GNATHANACANTHIDAE}

Views on the familial status of the fish now known as Gnathanacanthus goetzeei Bleeker, 1855 - notable synonyms of which are Haloxenus cuteneus Gunther, 1876, H. guntheri Johnston, 1883 (both with Tasmania as type locality), Beridia flava Castelnau, 1878 (Victoria) - have varied. Bleeker and Boulenger referred it to the Scorpaenidae, Gunther with some doubt placed it among the Cirrihitidae, Macleay listed it, as Gunther's species among Scorpaenidae (species 299), as Castelnau's with platycephalids and triglids in the old broad Cottina (species 466), Johnston in 1883 included it in Triglidae, in 1891 in Scorpaenidae. By recent Australian authors $S$. goetzeei has been treated as the sole representative of its family, Gnathanacanthidae. However, Greenwood et al. (1966) in their provisional classification of living teleosts subsume Gnathanacanthidae in Pataecidae. There is certainly considerable superficial similarity between on the one hand Gnathonaconthus and on the other the genera of the Pataecidae sensu stricto (Pataecus Richardson, 1844, Neopataecus Steindachner, 1884, Aetopcus Scott, 1936). And while there is undeniably much to be said in favor of a general policy of overa11 reduction in the large assemblage of families that have from time to time been proposed, a good case also can be made out for the retention of a family, even though monotypic, if the relevant form presents a constellation of taxonomically significant characters no one of which is exhibited by any of the other forms. Noteworthy differences between Gnathanaconthus and the pataecids s.s. include: ventrals present (absent in pataecids); dorsals separate, or virtually so with a deep notch between them, each rising to its greatest height near its middle (dorsals wholly united, combined contour nearly straight or a continuous fairly gentle curve); second dorsal subequal to (shorter than) first, with several (no) spines; anal base subequal to (much less than) first dorsal base. Osteological data are unavailable: on the basis of general external features, the writer would be inclined to favor the retention of Gnathanacanthidae.

\section{Genus GNATHANACANTHUS Bleeker, 1855}

Gnathanacanthus Bleeker, 1855, Verh. K. Akad. Wet. Amsterdam, ii, 21. Haplotype, G. goetzeei Bleeker.

Gnathanacanthus goetzeei Bleeker, 1855

Gnathanacanthus goetzeei Bleeker, 1855, Verh. K. Akad. Wet. Ansterdam, ii, 21. Type locality, Tasmania.

Materia1. Some observations are here made on five individua1s: (a) Ls 190, Lt 260, Bicheno, 26 February 1959, F.J. White; (b) Ls 235, Lt 315, east coast of Cape Barren Island, Bass Strait, 2 July 1969, B. Greeno, Q.V.M. Reg. No. 1969/5/28; (c) Ls 256, Lt 320, Ocean Vista, West Burnie, 2 October 1972 , C. Jones and P. Van Der Woude, Q.V.M. Reg. No. 1972/5/605; (d) Ls 218, Lt 288, off Eddystone Point, 27 December 1972, G. Allen (netted over gravel), Q.V.M. Reg. No. 1973/5/5; (e) Ls 201, Lt 206, Tamar River estuary, 17 September 1973, E. Porter and A.W. Hesketh, Q.V.M Reg. No. 1973/5/109.

Meristic characters. (Specimens in sequence as above). D. VII; V, 9: VIII; III, 10: VII; IV, 10: VII; III, 10: IX; IV, 9. A. III, 8 (all specimens). P. 11: 10 1eft, 11 right: $11: 11: 12$. C. $12+2: 9+3: 12+2: 10+2: 10+2$. V. I, 5 .

In describing his material Johnston $(1883,114)$ listed it as Holoxenus cutaneus and expressed the opinion it was probably correctly attributed (noting that if a new species was involved he proposed for it the name $H$. gunthemi), but called attention to noticeable differences between his dorsal and anal formulae and those of Günther. 
The variation in the dorsal count may be considered first. Along with those for our five specimens there may be noted those reported by Günther (1876) (Hozoxenus cutoneus) VII; III, 10, Johnston (1883) (H. guntheri) VIII; V, 10, Castelnau (1878) (Beridia flava) VII; III, 10 (in generic diagnosis VIII), Waite (1929) VII; V, 9, Scott (1962) (synoptic) VII; III, 10-11. So marked a variation in spine counts (VII-IX in first dorsal, III-V in second; overall 10-13 items) appears somewhat surprising. It is pertinent to note the two dorsals are variously reported either as being wholly separate (interdorsal not exceeding an eye diameter, according to Castelnau's account and plate), or as being 'separated by' a small space while being 'connected by a very low membrane' (Waite). Examination of our material discloses the following situation: where the space between the last largish spine ( 7 th or 8 th) of the first dorsal and what may conventionally regarded as the first spine of the second dorsal is bridged by a relatively low, but distinct membrane it will normally include one or two spines; where the membrane is obsolete or obsolescent (the interval between successive spine bases here ranging from rather less than to more than twice the diameter of the eye) there occur one or two small white-tipped non-rigid papillae that appear, by location and appearance, clearly to be rudiments of spines. Accordingly as these remain small soft projections (the height of which may not much exceed a millimetre) or develop into recognizable spines, of varying lengths, the first dorsal count is likely to be recorded as ranging from VII to IX. Furthermore, while the initial spines of the second dorsal are sometimes recognizable as such by being set more closely together than the terminal spines of the first dorsal, as in the specimen figured by waite, this arrangement is not always apparent; it is hence by no means impossible that the nominal differentiation between the two dorsals, if based wholly on a determination, not always readily made, of the lowest point on the membrane, where this is present, may at times be an arbitrary one, with the possibility of a spine, or spines, being allotted to either section of the fin.

In the anal Günther recorded 9, noting no spines, while Castelnau in the diagnosis of Beridia states the anal has one spine, but he describes and figures his type specimen of $B$. flava from Portland Bay, Victoria as having two spines. The normal count is III, 8-9, and it may be surmised Günther's notation is simply a slip, while Castelnau's II is either derived from an unusual specimen or is also an error. The pectoral has 10,11 (modally) or 12 rays. Castelnau describes and figures one upper branched ray plus nine simple rays: Waite states all rays are simple, but notes the upper two are conjoined at the base. Conjunction or very close approximation appears to characterize our material: however, the partial concealment of the rays by thick membrane may lead to there being the appearance of a single ray bifurcated in its distal two-thirds or so. The caudal is variously described and figured as having 10-14 rays. The norm is two moieties each of 5 or 6 rays reaching to the hind border, supplemented by two flanking shorter rays, one above, one below. As in the fins in general the anal rays are characteristically simple, though Castelnau notes and figures one divided ray. In the present specimens the caudal is rounded, as in Waite's plate, not straight, as in Castelnau's.

Dimensions as TLs. The data are for (a)-(e), in that order. Length, to origin, termination (1ast spine) of: first dorsal 150,149,148,183,149; 511,447,441, 495, 498: second dorsal (spine-ray) 526, 562, 551, 569, 567;884,851,863, 922, 801: anal (spineray) $539,566,621,660,602 ; 863,847,832,807,826$. Length to origin of: pectoral $237,268,273,275,249$ : ventral 266, 298, 320, 317, 269. Length of: pectoral 395, 349, 355, 393, 363: ventral 337, 294, 277, 307, 264. Head 392, 396, 359, 427, 408. Snout $129,116,111,138,129$. Eye (ful1) 48, 64, 59, 69, 70; (free of membrane) 26, 30, 35, 34,29 . Interorbital $76,89,94,78,80$. Depth at: front af eye 289, 238, 219, 289, 282 ; back of eye $326,311,313,358,335$; opercular border $368,383,336,413,433$; vent $405,336,340,394,398$ : maximum depth 405, 383, 340, 413, 448: depth of canda1 peduncle $92,86,79,89,81$.

Comparative proportions. A comparison of our material with that of Waite in respect of the proportions he records is here given (Waite's values in parentheses). Head 2.55, $2.53,2.78,2.34,2.45$, (2.2); depth $2.47,2.61,2.94,2.42,2.23,(2.6)$; length of caudal $2.71,2.84,3.84,3.11,3.40,(2.4)$, in standard length. Eye (for our specimens 
first entry is total diameter, second diameter of exposed portion) 8.28, 14.9; 6.20, 13.3; $6.13,10.2 ; 6.20,12.7 ; 6.23,14.1$, (9.5; measurement convention not specified; on basis of figure, probably exposed region); interorbital 5.14;4.43,4.18, 5.47, 5.13 (7.7); snout $3.04,3.32,3.23,3.10,3.15$ in head. Longest dorsal spine - (imperfect), 1.57 , $1.43,1.72,1.61(1.7)$; longest dorsal ray $1.31,1.23,1.62,1.36,1.32(1.36)$; second anal spine $3.39,3.51,2.97,3.58,3.04(2.8)$; longest anal ray $1.55,1.41,1.44,1.35$,
$1.58(1.6)$ in head.

Other features. Comparison of some non-metrical features in Waite's account of his Victorian specimen and in the Tasmanian examples reveals good overall agreement: variations, if any, shown by our $f$ ish are noted in parentheses. Maxilla extends to 'below first third of eye' (in (a) somewhat beyond middle of eye, in (b)-(e) short of eye by 0.1-0.3 eye diameter); dorsal commences at the angle over the eye; third dorsal spine longest; third and fourth (fourth) dorsal ray longest; dorsal and anal terminate almost evenly (fairly evenly, but some difference, according as determined by points of insertion of last rays or by termination of membrane); fourth and fifth anal rays longest, equal (fourth exceeds $f$ ifth); spine, second ray, third ray of ventral equal (subequal) to second spine and to fourth, fifth rays of anal. Waite records $4+8$ gill rakers on anterior arch; noting 'the first four of the lower limb are paired' (in one fish 5 , in the remainder all 8, of the rakers of the lower limb are paired; the inner rakers being smaller than the outer, with the interval between them about equal to the basal width, whereas the outer are contiguous or almost contiguous basally, and set nearly at right angles to the outer, upper series, thus projecting more or less horizontally into the pharynx. Neither Waite nor Castelnau makes mention of a large strong membrane - noted in Scott (1962, 164) - that joins the inner rays of the ventrals, and attaches them to the body, along which it extends on eitner side as a well developed slip about to level of vent, and as a ridge, becoming progressively obsolescent caudad, about to level of anal origin. The extent of the membranous junctions of the dorsal and anal with the caudal peduncle varies a good deal, ranging between the extremes shown in the figures of Castelnau and Waite.

Coloration. The fish, which always presents a bright appearance, is reported either as being unicolor (scarlet, deep purple, bright red, orange, yellow) or as exhibiting a combination, in varying proportions, of one of the reddish and one of the yellowish hues. Specimens (e) and (a) provide examples of the two types.

In the Tamar River specimen, (e), the whole body is a virtually uniform dark rich 'tapestry' red. Head not differing sharply from body, being slightly brownish red; all fins concolorous with head, though on being held up to the light they approach the richer, almost glowing body color.

The following notes on the Bicheno specimen, (a), were made quite shortly after capture. Head wholly rich red, apart from a median strip on forehead, from mouth to dorsal origin, the hind part of the chin, and the whole throat, which are bright yellow. Body wholly rich red, save for an extension of the yellow of the throat to below, and on to the base of, the pectoral. First dorsal more than half covered by a continuation of the head red; between first and second spines continuous red of any intensity confined to basal one-sixth, rest of membrane yellow with small red spots; between second and third spines similar, but spots more numerous; between third and fifth spotting much more profuse, giving a predominant effect of red, extending from base to within 2-5 mm of free border; between short posterior spines continuous red. Second dorsal, proximad of a line from about tip of second spine to near base of last ray, red; distad of this line yellow; membrane behind last ray almost entirely red. Anal, proximad of an upwardly concave line from near tip of first ray to middle of last ray, red; rest yellow. Ventral with about proximal one-third, pectoral with about proximal two-thirds red; rest of these fins yellow.

Spine and ray patterns. These have been investigated in the Eddystone Point individual, and it has been found possible to specify the lengths of all spines and rays (one caudal ray imperfect) as a function of their serial insertion along the fin base (see Part XIX 
for a general discussion of these length-number patterns). While a conventional origin and a conventional direction for the counting of the radial elements were specified in Part XIX for dorsal, anal, pectoral and ventral fins, no such conventions were there laid down for the caudal. It is here stipulated that in these investigations the formal first caudal ray is the dorsalmost ray and that the rays are counted from this ray continuously to the ventralmost (the frequency in the caudal of a bilateral symmetry of course suggested a possibility of treating the fin as composed of two moities with separate notations - however, the formulation adopted is evidently of a more general character, and is, moreover, in accord with the paradigms for the other fins).

Sets and subsets of the radial elements of this fish are as follows (as before, capitals denote spines, lower case letters rays).

$D=D_{1} \quad D_{2} \quad D_{3}=: D_{1}=x / x=$ I-III of first dorsal $; D_{2}=x / x=$ IV-VII of first dorsal ; $D_{3}=x / x=$ I-III of second dorsal. $d_{1} d_{2} d_{3}=: d_{1}=x / x=$ $1-4 ; d_{2}=x / x=5-7 ; d_{3}=x / x=8-10$.

$A=x / x=$ I, II, III . $a_{1} a_{2}=: a_{1}=x / x=1-4 ; a_{2}=x / x=5-8$.

$v=x / x=2-5$. (No formulation for ray 1 or spine). (Left fin measured).

$p=p_{1} \quad p_{2}=: p_{1}=x / x=1-4 ; p_{2}=x / x=5-8 . \quad$ (Left fin measured).

$c=c_{1} \quad c_{2}=: c_{1}=x / x=1-6 ; c_{2}=x / x=8-12,7$ imperfect.

Below there appear, for each subset, first, the regression equation for log spine or ray length on log serial number; secondly, measured lengths, mm, of the members of the subset (with, in parentheses, estimated lengths computed from the equation); third$1 y$, the $t$ value.

$D_{1} \cdot \log L=0.4365 \log N+1.5268$.

$D_{2} . \log L=0.70489 \log N^{1}+1.2537$.

$D_{3} . \log \ddot{L}=0.6564 \log N+1.1986$.

$d_{1} . \log L=0.1764 \log N+1.7387$.

$d_{2} . \log L=0.2388 \log N^{1}+1.6987$.

$a_{3^{*}} \log L=0.7737 \log N^{1}+1.1777$.

A. $\log L=0.6153 \log N+1.2340$.

$a_{1^{\circ}} \log L=0.08949 \log N+1.7829$.

$a_{2^{\cdot}} \log L=0.6966 \log N^{1}+1.3610$.

v. $\log L=0.3430 \log N+1.5609$.

$E_{1} \cdot \log L=0.2082 \log N+1.7509$.

$p_{2} \cdot \log L=0.3575 \log N^{1}+1.5505$.

$c_{1} \cdot \log L=0.1810 \log N^{I}+1.7168$.
$33.5(33.6), 46.0(45.5), 54.0(54.3) . t=18.39$.

$17.9(17.9), 29.1(29.2), 39.7(38.9), 47.0$

(47.6). $t=41.49$.

$15.8(15.8), 24.9(24.0), 32.5 .(32.5) t=$ 415.00 .

$54.6(54.8), 62.0(61.8), 67.0(66.4), 69.2$ $(69.8) . t=20.56$.

$49.9(50.0), 59.2(59.0), 64.8(65.0) . t=$ 38.14 .

$15.0(15.1), 26.0(25.7), 35.0,(35.2)$.

$t=48.77$.

$17.2(17.1), 26.0(26.3), 33.9,(33.7) . t=$ 43.03 .

$60.9(60.7), 64.0(64.5), 67.0(66.9), 68.9$ $(68.7) . \quad t=15.27$.

$23.1(23.0), 36.9(37.2), 48.9(49.4), 61.0$ $(60.3) . t=8.14$.

$36.6(36.4), 45.6(46.1), 53.0(53.0), 58.9$ $(58.5) . \quad t=24.18$.

$55.9(56.4), 66.1(65.1), 71.0(70.8), 74.5$ $(75.2) . \quad t=15.53$.

$36.0(35.5), 44.1(45.5), 52.2(52.6), 58.6$ $(58.3), 64.9(63.1), 68.1(67.4), 70.0(71.2)$. $t=16.37$.

$50.9(52.1), 60.7(59.1), 65.6(63.6), 07.2$ $(67.0), 69.0(69.7), 71.0(72.0) . t=10.54$. 


$$
c_{2} \log L=0.1681 \log N^{1}+1.7281
$$

$$
\begin{aligned}
& -(-)[\text { imperfect }], 60.2(61.3), 64.0 \\
& (64.3), 67.6(67.5), 70.2(70.1), 72.2 \\
& (72.3) . \quad t=14.93 .
\end{aligned}
$$

\section{Fami $1 y$ ALUTERIDAE}

In Part IX (1960) there was presented a key to 16 species reported from Tasmania this formulation was based largely on synoptic ad hoc data from available descriptions and figures, and was noted as being of a decidedly provisional character. The Tasmanian leatherjacket fauna remains in urgent need of revision, and at the present time no satisfactory census of it can be made.

Since the publication of that key, one item, a new species, Brachyluteres wolfei Scott, 1969, has been added to the 1ist; a South Australian form, Navodon multiradiata (Günther, 1870) is here recorded. From Brachyluteres trossulus (Richardson, 1846), appearing in the key in section $B$, the new species may be distinguished by having dorsal spine originating behind ( $c f$. before middle of) eye, by higher fin counts for dorsal and anal, 27, $25(24,22)$, and by lacking black specks and white or blue spots tending to form lines on lower part of body. Navodon multiradiata is separable from both species in section $G$ of the key, there 1 isted as Meuschenia trachylepis (Günther, 1870) and Navodon hippocrepis (Quoy \& Gaimard, 1824), by the following characters: dorsal spine inserted behind ( $c f$. above or before) middle of eye, spine not received (received) into a groove when depressed (this last feature also separates off another species, AcanthaZuteres brownii (Richardson, 1846) with spines (4) on caudal peduncle); gill opening almost wholly behind (wholly or mostly below) eye; distinctive color patterns.

Genus NAVODON Whitley, 1930

Navodon Whitley, 1930, Aust. Zool., vi, 2, 179. Orthotype, Balistes custralis Donovan.

Navodon multiradiata (Gunther, 1870).

Monocanthus multiradiatus Gunther, 1870, Cat. Fish. Brit. Mus., viii, 248. Type locality, South Australia.

Tasmanian record. Two examples, (a) Ls 260, Lt 320, Q.V.M. Reg. No. 1973/5/11, (b) Ls 267, Lt 329, Q.V.M. Reg. No. 1973/5/12, from about $3 \mathrm{~km}$ east of Wynyard, 7 January 1973 , North West Scuba Club (P. Van Der Woude).

The species was originally described from a stuffed and dried specimen, the color being given simply as 'uniform brownish grey'. In his South Australian catalogue Scott $(1962,316)$, who states it is not uncommon in the neighborhood of Dangerous Reef, off Port Lincoln, notes some additional morphological characters, and provides some observations on the color in life: a more detailed account is here offered. The Check-1ist records it (as Meuschenia multiradiatus) only from South Australia. Though here for the first time formally reported from this State, it is tolerably familiar to local scuba divers under the name of Spinytail (a name possibly applied, however, also to other species).

Fin counts. (Reported range in parentheses). D. $35,35(34-36)$. A. 33,33 (32-35) . P. 14/14, - / 13 (13). C. 12, 12 (12).

Proportions as TLs. Length to origin, termination of first dorsa1 275, 270, 381, 378; of second dorsaT $527,509,885,865$; of anal 585, 588, 907,899. Length to pectoral 315 , 301; length (ful1) of fin 125, 124; vertical extension of base 58, 56. Length to vent (middle) 575, 577. Head to lower end of gil1 opening 292, 273; to upper end 315 , 300. Snout 235,225 . Eye 62,56 . Interorbital 80,75 . Oblique length of gill opening 77,71 ; of mouth cleft 54,58 . Direct distance from eye to gill opening 87,82 ; to horizontal level of profile 31, 26; to nostril (middle) 38, 40; to base of dorsal spine 46, 37. Internarial 46, 49. Depth at gill opening 358, 352; at second dorsal origin 
375, 371; at vent (middle) 358, 352 (maximum depth): depth of caudal peduncle $88,96$. Length of dorsal spine - , 199; of first, longest, 1ast rays of dorsa1 46, 41, 100, 105 (about middle), 42, 48; of ana1 57, 39, 104, 103 (about middle), 54, 54; of pectoral $43,46,87,77(4 \mathrm{th}-5 \mathrm{th}), 50,55$ : direct length of longest (outermost) cauda1 ray 235, 228 , of shortest (midd1e) 150, 161. Length of pelvic spine 13, 17; basal diameter 11, 11: direct distance from spine to vent (midd1e) 63, 60 .

Description. Rather elongate, robust; greatest depth 2.6 , depth at ana 1 origin 2.3 , in Ls; not great1y compressed, maximum width half depth at anal origin. Dorsal profile more or less a single moderately convex sweep with slight local extra convexity above eye and some flattening at interdorsal; anal profile subequal to dorsal, the ventral flap sma1l, not extending far below level of beginning of tail. Pelvic spine well developed, reaching to within less than one and a half eye-diameters of vent; ventral spine sma11, mounded, length about one-fourth to one-third eye, with cluster of closely set blunt spinules, its distance from vent (middle) about equal to eye. Caudal peduncle shortish, rather stout, its depth subequal to interval between bases of last dorsal and uppermost caudal ray.

Head moderate, its length to top of gill opening 3.2-3.3 in Ls. Snout 1.3 in head, tip bluntly rounded. Eye 5.1-5.3 in head, close to dorsal profile, vertically below it by its own diameter. Interorbital moderately convex anteroposteriorly, strongly so transversely, 1.3 eye, one-fourth length to pectoral. Gill opening oblique, its lower end at, or barely anterior to, its upper end slightly behind, posterior border of orbit; its oblique length a trifle less than its distance from orbit, subequal to interorbital width. Nostril a little above level of middle of eye, its direct distance from orbit 1.4-1.6 in eye diameter, a little greater than its direct distance from its fellow. Mouth cleft somewhat oblique, its length subequal to eye. Teeth in lower jaw 4 , large, wide, flattened, the anterior pair larger, each with a deep groove basally on labial surface; teeth in upper jaw 6 , outer 4 small chisel-like, inner 2 subtriangular, much larger, though half, or less, size of median pair of lower jaw, the latter apposing all 6 of upper jaw.

Dorsal spine fully erectile; when depressed, not received into a groove (interdorsal somewhat concave mesially in its anterior half, but no groove here); originating just behind middle of eye; curved a little proximally, its distal three-fifths virtually straight; its length 1.2 interdorsal, about half maximum depth of body; rather slender, compressed anteroposteriorly, its thickness at base about three-fourths, at middle of length about half, its width there; posterior surface flattened; anterior surface strongly convex transversely, bearing in most of distal half two rows of small, largely recumbent spines, separated by a narrow well-marked groove, the spines becoming obsolete and the groove disappearing in the proximal half, the whole surface thickly beset with small elevations, mostly mammilloid, of several sizes, disposed partly at random, but in places arranged in two or three imperfect rows on either side; each lateral border with a row of about a score of subconical spines, slightly recurved, projecting outwards and downwards, the largest, occurring shortly above the base, about $2 \mathrm{~mm} 1$ long, set about twice its length from next spine, length of spine and interval between spines both noticeably decreasing distad.

Second dorsal originating at about middle of standard length, terminating above fourth anal ray from end; subrectangular, the rays, other than three or four at either end, of nearly the same length; longest ray, near middle of fin, $1.6-1.8$ eye; rays simple; between successive rays membrane gently excavate. Anal originating below sixth dorsal ray; similar in form to that fin. Pectoral situated wholly behind vertical from eye; its length 2.4-2.5 in head; upper half rounded, lower half continuing in a slower curve; longest (4th-5th ray) 1.4-1.6 eye; vertical extent of base subequal to eye, midpoint of base level with, or a trifle below, bottom of gill opening. Caudal slightly emarginate, gently sinuous, with one median convexity, two lateral concavities; longest (outermost) ray about four-fifths head, $1.4-1.5$ shortest (middle) ray. 
On middle of caudal peduncle on each side, in (a) 6 stout subconical forwardly curved spines, 3-3.5 mm long, in 3 pairs, about their own length apart longitudinally, rather more than this transversely: in (b) 4 spines only, somewhat stouter, less hooked; on both sides, nore pronouncedly on the right, each lower spine inserted in advance of the upper member of the pair, its normal position being vertically below it. While 6 is the modal number, instances of 4,5 or 6 have at various times been noted in the field. The species is described as having 'short bristles on the side of the tail' (Gunther), 'a small patch of very short bristles in front of the spines' (Scott). Our specimens present no macroscopic bristles, but just in advance of the spines an ill-defined subelliptical region, its major (longitudinal) axis about two-thirds eye, bears numerous almost microscopic projections, mostly black, many tipped white, that appear to differ little, except in size, from the microscopic spinules of the scales. Most of latter surmounted by a rounded fleshy papilla; on head irregularly disposed, larger, more closely set just behing light circumoral band; on trunk in a line along scale border, in most parts modally 7 in a series, but on most of flank behind about middle of anal base commonly $3-5$.

Coloration. The stuffed type was described as uniform grey; a lighter area at base of caudal spines and at hind margin of caudal: our formalin material shows remains of color pattern as follows. General color darkish grey on back and flank down about to level of gill opening, with a less intense extension downward behind head to near ventral profile; elsewhere lighter; a putty-colored circumoral ring; widish raised rim of vent off-white; between snout and vent four longitudinal series of dark markings, anteriorly mostly of spots or more or less rounded blotches, posteriorly coming to form short bars and some tolerably long lines, more or less continuous behind vent with several longitudinal series alongside anal base; two or three similar series along dorsal profile backwards about from level of dorsal spine to origin of second dorsal, with indications of extension to near end of fin; membrane of first dorsal only partly preserved in both specimens, remnants blackish, with some lighter spots; second dorsal and anal membranes virtually uniform pale yellowish, rays a trifle deeper; pectoral membrane hyaline, rays light yellowish; outer rays of caudal blackish, inner whitish and/or greenish, membrane between outer rays blackish, between inner rays either blackish throughout or only distally; a large yellowish semilunar terminal area, extending whole width of fin, its median anteroposterior extent a little less than an eye diameter.

Field notes on two fresh examples (near Wynyard, Wellington, $17 \mathrm{June} 1972$ ): 1ight greenish, some diffuse yellow round bases of caudal spines; blue markings round eye; blue circumoral ring, lips lighter; gold reticulations and lines on snout, continued on to lower flank as far back as vent, lines becoming further apart caudad; along anal base two blue, two gold lines; first dorsal blue marbled with black; second dorsal and anal bright yellow; pectoral yellow, somewhat olivaceous; caudal mostly dark greenish, light bluish area distally.

\section{REFERENCES}

Berg, L.S., 1940: The classification of fishes both recent and fossil. Trav. Inst. Acad. Sci. U.R.S.S., 5, 2, 86-517, figs 1-190: ed. in Russian and English issued by J.W. Edwards, 1947, Ann Arbor, Mich., U.S.A.

Boulenger, G.A., 1910: Fishes (systematic account of Teleostei) in Combridge Natural History, VII, 421-760, figs 240-440. London, McMillan \& Co.

Castelnau, F.L., 1878: Australian fishes. New or little known species. Proc. Linn. Soc. N.S.W., ii, 3, 225-248, p1s i-ii.

Greenwood, P.H., Rosen, D.E., Weitzman, S.H., \& Myers, G.S., 1966: Phyletic studies of teleostean fishes, with a provisional classification of living forms. BUZZ. U.S. Mus. nat. hist., 131, 4, 339-456, pls 21-23, text fig 1-9, charts 1-32. 
Günther, A.C.L.G., 1876: Remarks on fishes, with descriptions of new species in the British Museum, chiefly from southern seas. Ann. Mag. nat. hist. (4), xvi i, 389-402. 1880: An introduction to the study of fishes. Edinburgh, A. E C. Black.

Haast, J., 1873: Notes on some undescribed fishes of New Zealand. Trans. N.Z. Inst., v, $272-275, \mathrm{pl}$. xvi.

Johnston, R.M., 1883: General and critical observations on the fishes of Tasmania with a classified catalogue of al1 known species. Pop. Proc. R. Soc. Tasm., (1882), 58-144.

1891: Further observations on the fishes and fishing industries of Tasmania, together with a revised list of indigenous species. Pap. Proc. R. Soc. Tasm., $(1890), 22-46$.

Jordan, D.S., 1923: A classification of fishes including families and genera as far as known. Stanf. publ., univ. ser., biol. sci., III, 2, i-x+77-243.

Lineaweaver, T.H., \& Backus, R.H., 1970: The natural history of sharks. London, Andre Deutsch.

Lord, C.E., 1923: A list of the fishes of Tasmania. Pap. Proc. R. Soc. Tasm., (1922), 60-73.

, 1927: A list of the fishes of Tasmania. J. pan-Pac. res. Inst., 2, 4, 11-16.

, and Scott, H.H., 1924: A synopsis of the vertebrate animals of Tasmonia.

Hobart, oldham, Beddome \& Meredith.

McCoy, F., 1879: Prodromus of the zoology of Victoria, decade IV. Melbourne, Government Printer.

McCulloch, A.R., 1911: Report on the fishes obtained by the F.I.S. 'Endeavour' on the coasts of New South Wales, Victoria, South Australia and Tasmania. Part i. Zool. res. Endeavour, 1, 1, 1-87, pls i-xvi, text figs 1-19.

, 1914: Report on some fishes obtained by the F.I.S. 'Endeavour' on the coasts of Queensland, New South Wales, Victoria, Tasmania, South and South liestern Australia, Part ii. Biol, res. Endeavour, 2, 3, 77-165, pls xiii-xxxiv, text figs 1-15.

, 1922: Check-1ist of the fish and fish-like animals of New South Wales. Part iii. Aust. zool. 2, 3, 86-130, pls 25-43.

, 1929: A check-1ist of the fishes recorded from Australia. Aust. Hs. Hem. 5, 1-4 (part 4, Index, 1930), i-ix + 1-534.

Macleay, W., 1881a: Descriptive catalogue of Australian fishes. Part Il. Proc. Linr. Soc. N.S.H., V, IV, 510-629.

, 1881b: Descriptive catalogue of Australian fishes. Part IV. Proc. Linn. Soc. N.S.W., VI, II, 202-387.

Munro, I.S.R., 1956: Handbook of Australian fishes, 3, 13-16. Fisher, news 2. (now Aust. fisher.), 15, 9.

1957a: Handbook of Australian fishes, 10, 41-44. Fisher. news?. (now Aust. fisher.), 16, 4. 
, 1957b: Handbook of Australian fishes, 13, 53-56. Fisher. news 2. (now Aust. fisher.), 16,7 .

1960: Handbook of Australian fishes, 35, 141-144. Fisher. news2. (now Aust. fisher.). 19, 10 .

Schmidt, E.J., 1928: The freshwater ee1s of Australia. With some remarks on the shortfinned species of Anguizla. Rec. Aust. Mus., 16, 4, 179-210, figs 1-14.

Schultz, L.P., E Stern, E.M., 1948: The ways of fishes. New York, D. van Nostrand \& Co.

Scott, E.O.G., 1934-1973: Observations on some Tasmanian fishes. Parts I-XIX: in this journal (except Part XVI, 1969, Aust. zool., 15, 2, 160-177, figs 1-2). Contributions here cited: 1934, Part I, 31-53, p1s VI-VIII, text figs 1-2. 1935, Part I1, 63-73, pl V. 1953, Part VI, 141-165, text figs 1-4. 1960, Part IX, 87-102, text fig. 1. 1970, Part XVIII, 33-50, text fig 1. 1974, Part XIX, 247-292, text figs 1-2.

- 1969: Description of Brachaluteres wolfei sp. nov. (Aluteridae) and first Tasmanian record of Urolophus paucimaculatus Dixon, 1969 (Urolophidae). Pap. Proc. R. Soc. Tasm. (1968), 103, 35-45, text figs 1-2.

Scott, T.D., 1962: The marine and fresh water fishes of South Australia. Adelaide, Government Printer.

Waite, E.R., 1906: Descriptions of and notes on some Australian and Tasmanian fishes. Rec. Aust. Mus., 6, 194-210, p1s xxxiv-xxxvi.

, 1921: Illustrated catalogue of the fishes of South Australia. Rec. S. Aust. Mis., 2, 1, 1-208, p1. 1, 293 text figs.

, 1924: Illustrations of and notes on some Australian fishes. Rec. S. Aust. Mus., 2, 4, 480-487, p1s 29-31.

, \& McCulloch, A.R., 1915: The fishes of the South Australian government trawling cruise, 1914. Trans. R. Soc. S. Aust., 39, 455-476, pls xii-xv, 1 text fig.

Whịtley, G.P., 1931: New names for Australian fishes. Aust. zool., 6, 4, 310-334, pls xxv-xxvii, 1 text fig.

, 1940: The fishes of Australia. Part 1. The sharks, rays, devil fish and other primitive fishes of Australia and New Zealand. Sydney, Royal Zoological Society of New South Wales.

, 1943: Ichthyological descriptions and notes. Proc. Linn. Soc. N.S.W., LXVIII, 2, 114-144, 12 text figs.

, 1948: A 1ist of the fishes of Western Austra1ia. W.A. Fisher. BuZZ., 2, 1-35, map.

, 1962: Marine fishes of Australia, vo1. 2. Brisbane, Jacaranda Press.

, 1964: A survey of Australian ichthyology: Presidential address. Appendix B, Name-1ist of the fishes recorded from Australia. Proc. Linn. Soc. N.S.W., LXXXIX, 1, 32-60.

, 1968: A check-1ist of the fishes recorded from the New Zealand region. Aust. zool., 15, 1, 1-102, figs 1-2. 